\title{
An improved method of modeling infiltration in commercial building energy models
}

\author{
Lisa C. Ng
}

Steven J. Emmerich

Andrew K. Persily

http://dx.doi.org/10.6028/NIST.TN.1829
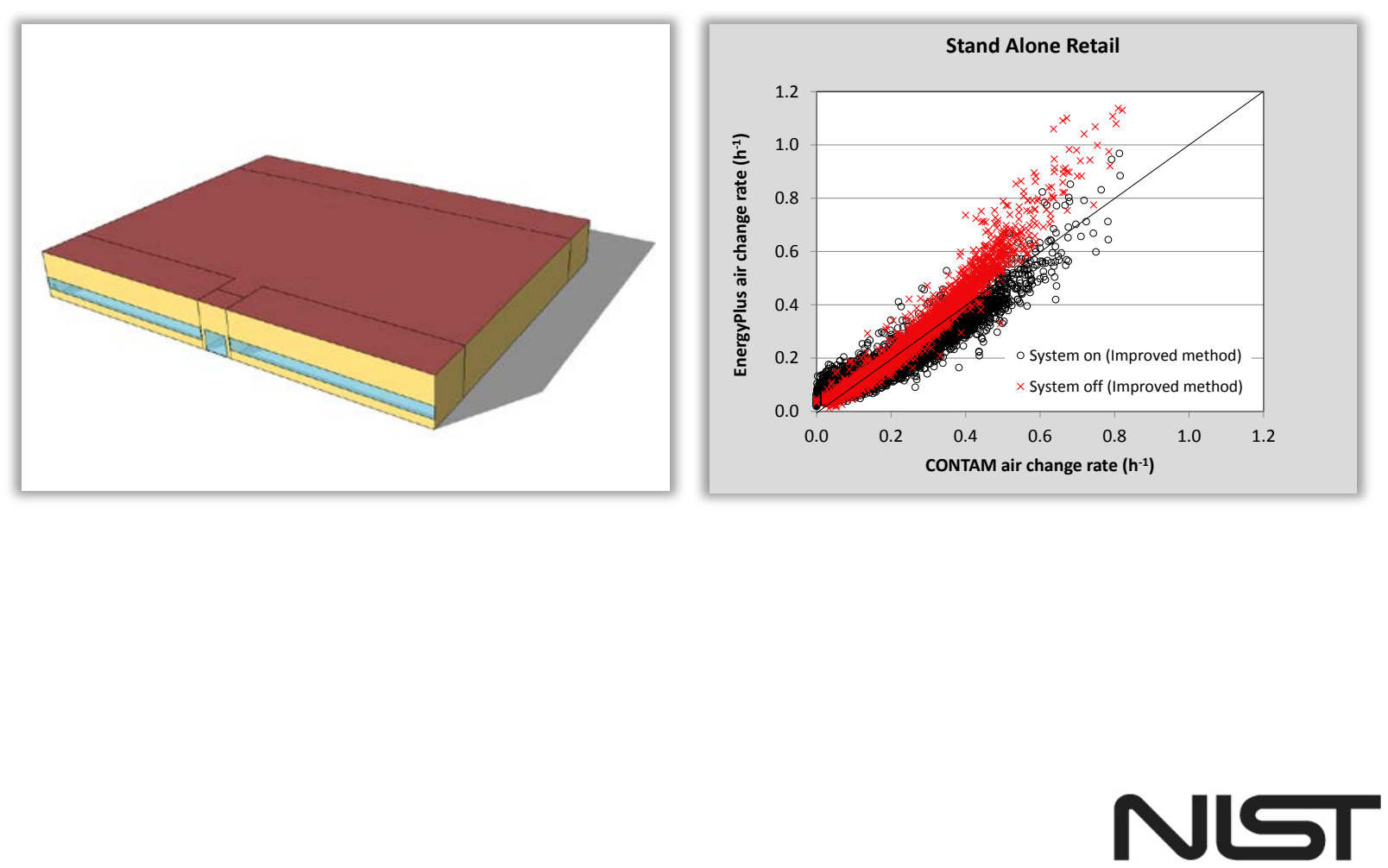

National Institute of Standards and Technology U.S. Department of Commerce 


\title{
An improved method of modeling infiltration in commercial building energy models
}

\author{
Lisa C. Ng \\ Steven J. Emmerich \\ Andrew K. Persily \\ Energy and Environment Division \\ Engineering Laboratory
}

http://dx.doi.org/10.6028/NIST.TN.1829

April 2014

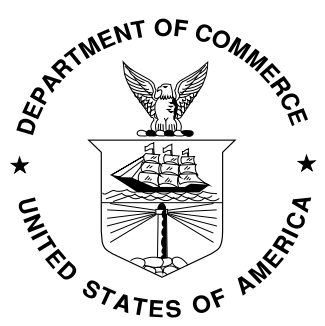

U.S. Department of Commerce

Penny Pritzker, Secretary

National Institute of Standards and Technology Patrick D. Gallagher, Under Secretary of Commerce for Standards and Technology and Director 
Certain commercial entities, equipment, or materials may be identified in this document in order to describe an experimental procedure or concept adequately. Such identification is not intended to imply recommendation or endorsement by the National Institute of Standards and Technology, nor is it intended to imply that the entities, materials, or equipment are necessarily the best available for the purpose.

National Institute of Standards and Technology Technical Note 1829

Natl. Inst. Stand. Technol. Tech. Note 1829, 41 pages (April 2014) http://dx.doi.org/10.6028/NIST.TN.1829 CODEN: NTNOEF 


\begin{abstract}
As building envelope performance and HVAC equipment efficiencies are increasingly improved to reduce building energy use, a greater percentage of the total energy loss of a building can occur through envelope leakage. Although the energy impacts of unintended infiltration on a building's energy use can be significant, current energy simulation software and design methods are generally not able to accurately account for envelope infiltration and the impacts of improved airtightness. New strategies to incorporate airflow calculations into building energy calculations are proposed, which are more accurate than current approaches in energy simulation software and easier to apply than multizone airflow modeling. The new strategies are based on relationships between infiltration rates calculated using multizone airflow models, building characteristics, including envelope airtightness, weather conditions, and HVAC system operation.
\end{abstract}

Keywords: airflow modeling, commercial buildings, CONTAM, energy modeling, EnergyPlus, infiltration 


\section{INTRODUCTION}

Heating, ventilating, and air conditioning (HVAC) systems in buildings are designed to maintain acceptable thermal comfort and indoor air quality (IAQ). The operating cost of these HVAC systems is often a large percentage of the total energy cost of buildings, which constitutes $40 \%$ of the primary energy consumed in the U.S. (DOE 2010). Due to the current emphasis on reducing energy consumption and greenhouse gas emissions, the use of energy simulation software has increased to investigate different design options and their impacts on building energy use. One design option to reduce building energy use is the improvement of building envelope airtightness. Existing data show that unless efforts are made to design and build tight building envelopes, commercial buildings are actually much leakier than typically assumed (Emmerich et al. 2007; Emmerich and Persily 2013). As a result, the energy impacts of uncontrolled infiltration are also greater than assumed. Nevertheless, current energy simulation software and design methods generally do not accurately account for envelope infiltration, and therefore the impacts of improved airtightness on energy may not be fully captured.

A review of the airflow analyses capabilities of the most widely used energy simulation software tools found that many of the empirical infiltration models employed in these tools are based on calculation methods developed for low-rise, residential buildings (Ng and Persily 2011). These methods are not generally appropriate for other types of buildings, particularly mechanically ventilated commercial buildings as well as taller buildings, which have more airtight separations between floors and vertical shafts. Also, these empirical infiltration models require the user to specify air leakage coefficients that are best obtained from building pressurization tests (ASTM 2010), and only limited air leakage data are available for commercial buildings (Emmerich and Persily 2013). Many energy simulation software users simply assume constant infiltration rates, which do not reflect known dependencies on indoor-outdoor conditions and ventilation system operation. Airflow calculations using existing theory and methods (Walton 1989) are the only technically sound means of determining the airflow rates for analyzing energy use as well as indoor air quality.

Considering the few energy simulation software tools that are able to simulate airflow using multizone airflow models, the capabilities are often limited and can be difficult for users to employ. The AIRFLOW NETWORK model in EnergyPlus is based on an early version of the National Institute of Standards and Technology's (NIST) multizone airflow and contaminant transport model CONTAM (Walton and Dols 2013) with restrictions on the type of analyses that it can perform. DesignBuilder implements limited capabilities of the EnergyPlus AIRFLOW NETWORK model. McDowell et al. (2003) describe a partial coupling of the multizone airflow model, CONTAM, with the transient system simulation program TRNSYS. More recently, NIST has updated the TRNSYS/CONTAM coupling to include the full multizone airflow and IAQ capabilities of CONTAM (available at http://www.bfrl.nist.gov/IAQanalysis/software/). The application of modeling approaches that couple airflow and thermal or energy analyses in actual building design, however, is limited.

Empirical approaches to estimating infiltration rates have the advantage of ease of use relative to multizone building airflow models. These empirical approaches employ algebraic equations that relate simple building features, such as height and envelope leakage, as well as weather conditions to calculate infiltration rates. One of the earliest such approaches was developed by 
Shaw and Tamura (1977), which had one equation for stack induced infiltration, one for wind driven, and another to combine the two into the total building infiltration rate. More recently, Gowri et al. (2009) proposed a method to account for infiltration in commercial buildings that was developed using a square medium-size office building and a building envelope airtightness value, such as one obtained by a pressurization test. Assuming a constant indoor-outdoor pressure difference of $4 \mathrm{~Pa}$, Gowri calculated an infiltration rate to be input into EnergyPlus using an approach that accounts for wind but not temperature effects. Note that those temperature effects can be important particularly in taller buildings and colder climates. Gowri recommends that this leakage rate be multiplied by a wind speed adjustment and by a factor of 0.25 in EnergyPlus when the HVAC system is on and 1.0 when the HVAC system is off. Overall, the method greatly simplifies the interaction of building envelope airtightness, weather, HVAC system operation, and infiltration.

In summary, the ways in which infiltration are currently accounted for in energy simulations are not typically based on well-developed airflow theory relating building envelope airtightness, HVAC system operation, and weather (Walton 1989). In those few energy simulation programs where airflow can be more accurately modeled, the features are often limited and cumbersome to employ and are rarely used in design. New strategies to more accurately, and more simply, incorporate physically-based infiltration calculations into energy software are proposed in this paper. These strategies are based on relationships developed between infiltration rates calculated by multizone airflow modeling, building characteristics, HVAC system operation, weather conditions, and building envelope airtightness. The strategies are described for implementation in EnergyPlus but are applicable to other energy simulation software. 


\section{METHODS}

Sec. 2.1 describes how infiltration is currently incorporated into EnergyPlus, though the approach is applicable to other energy simulation software. Sec. 2.2 describes new strategies for estimating infiltration in mechanically ventilated commercial buildings based on detailed multizone airflow simulations in buildings. Sec. 2.2.1 describes a building-specific strategy, and Sec. 2.2.2 describes a generalized one. In the building-specific strategy, the results of multizone airflow simulations are fit to an empirical relationship between infiltration rates and weather conditions for individual buildings. For the generalized strategy, the coefficients of the empirical relationships calculated in Sec. 2.2.1 are related to general building characteristics, such as building height, in order to derive expressions for calculating empirical coefficients for any given building.

\subsection{Current strategy for modeling of infiltration in EnergyPlus}

EnergyPlus uses the following empirical equation to calculate infiltration:

$$
\text { Infiltration }=I_{\text {design }} \bullet F_{\text {schedule }}\left[A+B|\Delta T|+C \cdot W_{\mathrm{s}}+D \cdot W_{\mathrm{s}}^{2}\right]
$$

where $I_{\text {design }}$ is defined by EnergyPlus as the "design infiltration rate", which is the airflow through the building envelope under design conditions. Its units are selected by the user and can be h $^{-1}, \mathrm{~m}^{3} / \mathrm{s} \bullet \mathrm{m}^{2}$ or $\mathrm{m}^{3} / \mathrm{s}$. To apply this infiltration approach in EnergyPlus, a value of $I_{\text {design }}$ is assigned to each zone, with the option of each zone being assigned a different $I_{\text {design }}$ value. $F_{\text {schedule }}$ is a factor between 0.0 and 1.0 that can be scheduled, typically to account for the impacts of fan operation on infiltration. $|\Delta T|$ is the absolute indoor-outdoor temperature difference in ${ }^{\circ} \mathrm{C}$, and $W_{\mathrm{s}}$ is the wind speed in $\mathrm{m} / \mathrm{s} . A, B, C$, and $D$ are constants, for which values are suggested in the EnergyPlus user manual (DOE 2013). However, those values are based on studies in low-rise residential buildings. Given the challenges in determining valid coefficients for a given building, a common strategy used in EnergyPlus for incorporating infiltration is to assume fixed infiltration rates. In other words, assume $A=1$ and $B=C=D=0$. However, this strategy does not reflect known dependencies of infiltration on outdoor weather and HVAC system operation. Therefore, new strategies are proposed in the following sections that can more accurately estimate infiltration in EnergyPlus and other energy simulation tools.

\subsection{Proposed strategies for improved modeling of infiltration in EnergyPlus}

\subsubsection{Method 1 - Building Specific}

Method 1 is a building-specific strategy for determining $A, B, C$, and $D$ values in Equation (1) by using the results of multizone airflow simulations. Seven commercial reference buildings (DOE 2011) were selected for testing this strategy: Full Service Restaurant, Hospital, Large Office, Medium Office, Primary School, Stand Alone Retail, and Small Hotel. These particular buildings were selected based on their being representative of different types of occupancy and HVAC systems in commercial buildings.

Models of these buildings have previously been created in the multizone airflow and contaminant transport model CONTAM (Walton and Dols 2013). Details of the CONTAM building models can be found in Ng et al. (2012) and (2013). In order to test the new strategies for modeling infiltration, Energy Plus models of the buildings were used. Details of the 
EnergyPlus building models can be found in DOE (2011). The building zoning was different between the CONTAM and EnergyPlus models in instances where the CONTAM models needed additional zones to support realistic airflow analyses. Zones that were added to the CONTAM models included restrooms, stairwells, elevator shafts, and storage rooms. Modeling all building zones, or at least more of the zones than are typically needed for energy analyses, is important for airflow and IAQ analyses in order to properly capture pressure relationships and airflow patterns in buildings. Though the number of zones and some zone floor areas are different between the CONTAM and EnergyPlus models, the total building floor areas and volumes are consistent. The CONTAM and EnergyPlus models employed the same occupancy and system operation schedules and outdoor air ventilation requirements. In addition, the outdoor air economizers and night-cooling options in EnergyPlus were disabled for all of the buildings since these capabilities were not implemented in the CONTAM models.

Hourly infiltration rates for one year were simulated for each building using weather data for Chicago (DOE 2011). Chicago weather was selected since there are a relatively high percentage of buildings in the U.S. in this climate zone (Deru et al. 2011) and because Chicago covers a wide range of outdoor temperatures and wind speeds. A building envelope effective leakage area of $5.27 \mathrm{~cm}^{2} / \mathrm{m}^{2}$ at a reference pressure of $4 \mathrm{~Pa}$ was used in the CONTAM models. This value was based on available airtightness data in U.S. commercial buildings (Emmerich and Persily 2005). Based on a constant indoor-outdoor pressure of $4 \mathrm{~Pa}$ and a pressure exponent of 0.65 , this leakage area corresponds to a building envelope leakage value of $0.00137 \mathrm{~m}^{3} / \mathrm{s} \bullet \mathrm{m}^{2}$ for use in Energy Plus. In this discussion, infiltration includes the outdoor air entering through unintentional building envelope leakage only. It does not include any outdoor air entering the building through mechanical ventilation systems.

The results of CONTAM simulations for each building are fit to Equation (1) to determine $A, B$, $C$, and $D$ values for the seven buildings. Note that the outdoor temperature EnergyPlus uses to calculate $|\Delta T|$ in Equation (1) is not the temperature from the weather file. Instead, EnergyPlus uses the zone (or local) outdoor dry-bulb, $T_{\text {local }}$, which is calculated as a function of zone height (DOE 2012):

$$
T_{\text {local }}=T_{\text {ambient }}+-0.0065 \bullet H_{\text {local }}
$$

where $T_{\text {ambient }}$ is the ambient temperature from the weather file, and $H_{\text {local }}$ is the height of a zone above ground level. The tallest building simulated in this paper was the Large Office (50.4 m), resulting in less than a $0.5{ }^{\circ} \mathrm{C}$ difference between $T_{\text {local }}$ and $T_{\text {ambient }}$ when calculated using Equation (2). Thus, when fitting CONTAM infiltration rates and weather data to Equation (1), it was assumed that $T_{\text {local }}=T_{\text {ambient }}$ for all buildings. The indoor temperature setpoint in the EnergyPlus models was set to $20{ }^{\circ} \mathrm{C}$ when the system was on. The indoor temperature in the CONTAM models was set to be $20^{\circ} \mathrm{C}$ all the time.

It should also be noted that the wind speed in Equation (1) that EnergyPlus uses is not the wind speed from the weather file. EnergyPlus uses a zone (or local) wind speed, $W_{\mathrm{s}}$, which is calculated as a function of zone height (DOE 2012): 


$$
W_{\mathrm{s}}=W_{\mathrm{met}}\left(\frac{\delta_{\mathrm{met}}}{z_{\mathrm{met}}}\right)^{\alpha_{\mathrm{met}}}\left(\frac{z}{\delta}\right)^{\alpha}
$$

where $W_{\text {met }}$ is the wind speed measured at the meteorological station, $\delta_{\text {met }}$ is the wind speed profile boundary layer thickness at the meteorological station, $z_{\text {met }}$ is the height of the wind speed sensor at the meteorological station, $\alpha_{\text {met }}$ is the wind speed profile exponent at the meteorological station, $z$ is the height of a zone above ground level, $\alpha$ is the wind speed profile at the site, and $\delta$ is the wind speed profile boundary layer thickness at the site. Equation (3) is used to scale the wind speed measured at a meteorological station off-site to the wind speed at the top of a building or higher, with this scaling dependent on nearby obstructions. Below the building height, the wind speed is a complex function of the geometry of the building and nearby buildings, limiting the accuracy of the adjustments in Equation (3) (ASHRAE 2009).

For each building, it was assumed that the meteorological station was located in "open, flat" terrain and the building was located in "city" terrain. The wind speed profile boundary layer thickness and wind speed profile exponent for flat terrain are $270 \mathrm{~m}$ and 0.14 , respectively, and for city terrain are $460 \mathrm{~m}$ and 0.33, respectively (ASHRAE 2009). Thus, Equation (3) can be simplified to:

$$
W_{\mathrm{s}}=0.2096 \cdot W_{\mathrm{met}} \mathrm{z}^{0.33}
$$

For buildings with multiple floors, EnergyPlus uses the value of $z$ for each floor in Equation (4). In order to simplify the fitting of CONTAM infiltration rates and weather data to Equation (1), an average "local wind speed adjustment" was calculated for each building. The "local wind speed adjustment" for each zone is defined using Equation (4) with $z$ equal to the zone height. For example, the heights of the zones in the Full Service Restaurant are $1.53 \mathrm{~m}$ and $3.89 \mathrm{~m}$, and the two local wind speed adjustments are 0.2412 and 0.3282 . The average local wind speed adjustment for the building is therefore 0.2847 . Thus, $W_{\mathrm{s}}=0.2847 \cdot W_{\text {met }}$ in Equation (1) for the Full Service Restaurant. The average local wind speed adjustments for all seven buildings are listed in Table 1.

Table 1. Average local wind speed adjustments

\begin{tabular}{|l|c|}
\hline Building & Average Local Wind Speed Adjustments \\
\hline Full Service Restaurant & 0.2847 \\
\hline Hospital & 0.4346 \\
\hline Large Office & 0.5823 \\
\hline Medium Office & 0.3705 \\
\hline Primary School & 0.2636 \\
\hline Stand Alone Retail & 0.3030 \\
\hline Small Hotel & 0.3642 \\
\hline
\end{tabular}

Using a spreadsheet program, CONTAM infiltration rates and the corresponding weather data over one year were fit to Equation (1) to calculate $A, B, C$, and $D$ values for each of the seven buildings. Since wind pressure on the surface of a building is a function of the square of wind speed (Walton and Dols 2013), a separate set of $A, B$, and $D$ values were calculated with $C$ set to 0 . 
The calculated $A, B, C$, and $D$ values (not shown) and $I_{\text {design }}=0.00137 \mathrm{~m}^{3} / \mathrm{s} \cdot \mathrm{m}^{2}$ were input into the EnergyPlus ZoneInfiltration:DesignFlowRate object, which implements Equation (1) for calculating infiltration. It was found that the infiltration rates calculated by EnergyPlus, whether $C$ was non-zero or zero, were similar. Therefore, to simplify the subsequent analyses, $C$ was set equal to 0 . The calculated $A, B$, and $D$ values, assuming $I_{\text {design }}=0.00137 \mathrm{~m}^{3} / \mathrm{s} \bullet \mathrm{m}^{2}$, for each of the seven buildings are listed in Table 2 . It was assumed that $A=0$ when the HVAC system was off because when $|\Delta T|$ and $W_{\mathrm{s}}$ are zero, the system-off infiltration rate should be zero. There are no system-off values for the Hospital and Small Hotel because the HVAC systems in these buildings were always on.

The Hospital, Large Office, and Medium Office had negative $A$ values. The rest of the $A, B$, and $D$ values were positive. Independent of the sign, all of the buildings have $A, B$, and $D$ values that are of the same magnitude except for the Full Service Restaurant. Its $A, B$, and $D$ values were about five to ten times greater than in the other buildings. This may be due to its large negative net system flow (discussed later in conjunction with Table 4), while the other buildings have positive net system flow. It may also be due to the presence of an attic space, which the other buildings do not have.

Table 2. Method 1: $A, B$, and $D$ values of simulated buildings $\left(I_{\text {design }}=0.00137 \mathrm{~m}^{3} / \mathrm{s}^{\bullet} \mathrm{m}^{2}\right)$

\begin{tabular}{|l|c|c|c|c|c|c|c|}
\hline & $\begin{array}{c}\text { Full } \\
\text { Service } \\
\text { Restaurant }\end{array}$ & Hospital & $\begin{array}{c}\text { Large } \\
\text { Office }\end{array}$ & $\begin{array}{c}\text { Medium } \\
\text { Office }\end{array}$ & $\begin{array}{c}\text { Primary } \\
\text { School }\end{array}$ & $\begin{array}{c}\text { Small } \\
\text { Hotel }\end{array}$ & $\begin{array}{c}\text { Stand } \\
\text { Alone } \\
\text { Retail }\end{array}$ \\
\hline $\boldsymbol{A}$ on & 0.1413 & -0.0535 & -0.0412 & -0.0283 & 0.0173 & 0.0374 & 0.0181 \\
\hline $\boldsymbol{B}$ on & 0.0197 & 0.0065 & 0.0012 & 0.0031 & 0.0047 & 0.0078 & 0.0074 \\
\hline $\boldsymbol{D}$ on & 0.1033 & 0.0151 & 0.0087 & 0.0280 & 0.0364 & 0.0275 & 0.0322 \\
\hline $\boldsymbol{A}$ off & 0 & NA & 0 & 0 & 0 & NA & 0 \\
\hline B off & 0.0255 & NA & 0.0141 & 0.0138 & 0.0068 & NA & 0.0099 \\
\hline $\boldsymbol{D}$ off & 0.1189 & NA & 0.0153 & 0.0315 & 0.0433 & NA & 0.0364 \\
\hline
\end{tabular}

Note: The Hospital and Small Hotel HVAC systems are always scheduled to be on.

The $A, B$, and $D$ values from Table 2 were then input into the EnergyPlus

ZoneInfiltration:DesignFlowRate object. $A_{\text {on }}, B_{\text {on }}$, and $D_{\text {on }}$ were used with $F_{\text {schedule }}=1.0$ during system-on hours and $F_{\text {schedule }}=0.0$ during system-off hours. $A_{\text {off }}, B_{\text {off }}$, and $D_{\text {off }}$ were used with $F_{\text {schedule }}=1.0$ during system-off hours and $F_{\text {schedule }}=0.0$ during system-on hours. Annual energy simulations were then performed using EnergyPlus for the same Chicago weather used in the CONTAM predictions. Hourly infiltration rates were then compared between CONTAM and EnergyPlus. The mean of the CONTAM and EnergyPlus infiltration rates are listed in Table 3, along with the standard error, standard error as a percentage of the CONTAM mean rate (or "relative standard error"), and coefficient of determination, $R^{2}$, of the EnergyPlus infiltration rates compared with the CONTAM rates.

The average system-on and system-off $R^{2}$ value for the seven buildings shown in Table 3 is 0.80 . Excluding the Hospital and Large Office, which have the smallest mean infiltration rates among the buildings, the average system-on relative standard error of the other buildings is $24 \%$ and the average system-off relative standard error is $15 \%$. As expected, the $R^{2}$ values and relative standard error of the EnergyPlus infiltration rates compared with CONTAM are relatively good using Method 1 because the $A, B$, and $D$ values were specifically calculated for each building. However, using Method 1 requires infiltration rate data, such as those generated using 
CONTAM or measured values, which may not necessarily be available in a given building. In order to address this limitation, a general method to calculate $A, B$, and $D$ in any building is described in Section 2.2.2.

Table 3. Comparison of CONTAM and EnergyPlus infiltration rates using $A, B$, and $D$ values from Table $2\left(I_{\text {design }}=0.00137 \mathrm{~m}^{3} / \mathrm{s}^{\bullet} \mathrm{m}^{2}\right)$

\begin{tabular}{|c|c|c|c|c|c|c|c|}
\hline & Restaurant & Hospital & $\begin{array}{l}\text { Large } \\
\text { Office }\end{array}$ & $\begin{array}{l}\text { Medium } \\
\text { Office }\end{array}$ & School & Hotel & Retail \\
\hline \multicolumn{8}{|l|}{ System on } \\
\hline $\begin{array}{l}\text { CONTAM mean } \\
\text { infiltration rate }\left(\mathrm{h}^{-1}\right)\end{array}$ & 0.53 & 0.02 & 0.03 & 0.11 & 0.25 & 0.26 & 0.23 \\
\hline $\begin{array}{l}\text { EnergyPlus mean } \\
\text { infiltration rate }\left(\mathrm{h}^{-1}\right)\end{array}$ & 0.48 & 0.06 & 0.03 & 0.14 & 0.24 & 0.29 & 0.24 \\
\hline $\begin{array}{l}\text { Standard error of } \\
\text { EnergyPlus rates }\left(\mathrm{h}^{-1}\right) \\
\text { (\% of CONTAM mean) }\end{array}$ & $\begin{array}{c}0.09 \\
(17 \%)\end{array}$ & $\begin{array}{c}0.02 \\
(87 \%)\end{array}$ & $\begin{array}{c}0.02 \\
(65 \%)\end{array}$ & $\begin{array}{c}0.04 \\
(35 \%)\end{array}$ & $\begin{array}{c}0.06 \\
(25 \%)\end{array}$ & $\begin{array}{c}0.06 \\
(22 \%)\end{array}$ & $\begin{array}{c}0.05 \\
(20 \%)\end{array}$ \\
\hline $\begin{array}{l}\text { Coefficient of } \\
\text { determination, } R^{2}\end{array}$ & 0.83 & 0.87 & 0.78 & 0.75 & 0.83 & 0.82 & 0.88 \\
\hline \multicolumn{8}{|l|}{ System off } \\
\hline $\begin{array}{l}\text { CONTAM mean } \\
\text { infiltration rate }\left(\mathrm{h}^{-1}\right)\end{array}$ & 0.50 & NA & 0.14 & 0.27 & 0.29 & NA & 0.26 \\
\hline $\begin{array}{l}\text { EnergyPlus mean } \\
\text { infiltration rate }\left(\mathrm{h}^{-1}\right)\end{array}$ & 0.43 & NA & 0.12 & 0.23 & 0.23 & NA & 0.23 \\
\hline $\begin{array}{l}\text { Standard error of } \\
\text { EnergyPlus rates }\left(\mathrm{h}^{-1}\right) \\
\text { (\% of CONTAM mean) }\end{array}$ & $\begin{array}{c}0.07 \\
(14 \%) \\
\end{array}$ & NA & $\begin{array}{r}0.02 \\
(15 \%) \\
\end{array}$ & $\begin{array}{c}0.05 \\
(18 \%) \\
\end{array}$ & $\begin{array}{c}0.05 \\
(18 \%) \\
\end{array}$ & NA & $\begin{array}{r}0.03 \\
(12 \%) \\
\end{array}$ \\
\hline $\begin{array}{l}\text { Coefficient of } \\
\text { determination, } R^{2}\end{array}$ & 0.83 & NA & 0.76 & 0.75 & 0.68 & NA & 0.88 \\
\hline
\end{tabular}

Note: The Hospital and Small Hotel HVAC systems are always scheduled to be on. The standard error of

EnergyPlus rates and $R^{2}$ values were based on the comparison between EnergyPlus and CONTAM results.

\subsubsection{Method 2 - General}

Method 2 is a generalized strategy for determining $A, B$, and $D$ values in Equation (1) based on key building characteristics. The building characteristics considered are: building height $(H$ in $\mathrm{m})$, exterior surface area to volume ratio $\left(S V\right.$ in $\left.\mathrm{m}^{2} / \mathrm{m}^{3}\right)$, and net system flow (i.e., design supply air minus design return air minus mechanical exhaust air) normalized by exterior surface area $\left(F_{\mathrm{n}}\right.$ in $\mathrm{m}^{3} / \mathrm{s}^{\bullet} \mathrm{m}^{2}$ ). The values for these characteristics for each of the seven buildings are listed in Table 4. It should be noted that only the Full Service Restaurant has a large negative net system flow (Table 4), while the other buildings have positive net system flows.

Table 4. Building characteristics of seven simulated buildings

\begin{tabular}{|l|c|c|c|c|c|c|c|}
\hline & $\begin{array}{c}\text { Full } \\
\text { Service } \\
\text { Restaurant }\end{array}$ & Hospital & $\begin{array}{c}\text { Large } \\
\text { Office }\end{array}$ & $\begin{array}{c}\text { Medium } \\
\text { Office }\end{array}$ & $\begin{array}{c}\text { Primary } \\
\text { School }\end{array}$ & $\begin{array}{c}\text { Small } \\
\text { Hotel }\end{array}$ & $\begin{array}{c}\text { Stand } \\
\text { Alone } \\
\text { Retail }\end{array}$ \\
\hline $\boldsymbol{H}(\mathbf{m})$ & 4.7 & 23.8 & 50.4 & 12 & 4 & 11.6 & 6.1 \\
\hline $\boldsymbol{S} \mathbf{V}\left(\mathbf{m}^{2} / \mathbf{m}^{3}\right)$ & 0.17 & 0.11 & 0.09 & 0.18 & 0.34 & 0.23 & 0.24 \\
\hline $\boldsymbol{F}_{\mathbf{n}}\left(\mathbf{m}^{3} / \mathbf{s}^{\mathbf{2}}\right) \times \mathbf{1 0}^{-3}$ & -2.6 & 1.0 & 1.3 & 0.56 & 0.02 & 0.50 & 0.21 \\
\hline
\end{tabular}

In order to determine values of $A, B$ and $D$ for any given building, the following relationships between these constants and the building characteristics $\left(H, S V\right.$, and $\left.F_{\mathrm{n}}\right)$ were considered: 


$$
\begin{aligned}
A & =M_{\mathrm{A}} \cdot H+N_{\mathrm{A}} \cdot S V+P_{\mathrm{A}} \cdot F_{\mathrm{n}} \\
B & =M_{\mathrm{B}} \cdot H+N_{\mathrm{B}} \cdot S V+P_{\mathrm{B}} \cdot F_{\mathrm{n}} \\
D & =M_{\mathrm{D}} \cdot H+N_{\mathrm{D}} \cdot S V+P_{\mathrm{D}} \cdot F_{\mathrm{n}}
\end{aligned}
$$

where $M, N$, and $P$ are constants, and their subscripts distinguish them between $A, B$, and $D$.

Using a spreadsheet program, the building-specific $A, B$ and $D$ values calculated using Method 1 (Table 2) and the building characteristics of the seven buildings (Table 4) were fit to Equations (5) through (7) to calculate $M, N$, and $P$. Equations (8) through (13) show the results for systemon and system-off conditions. It was assumed that $A=0$ and the net system flow is zero $\left(F_{\mathrm{n}}=0\right)$ when the system is off.

$$
\begin{gathered}
A_{\text {on }}=0.0001 \cdot H+0.0933 \cdot S V+-47 \cdot F_{\mathrm{n}} \\
B_{\text {on }}=0.0002 \cdot H+0.0245 \cdot S V+-5 \cdot F_{\mathrm{n}} \\
D_{\text {on }}=0.0008 \cdot H+0.1312 \cdot S V+-28 \cdot F_{\mathrm{n}} \\
A_{\text {off }}=0 \\
B_{\text {off }}=0.0002 \cdot H+0.0430 \cdot S V \\
D_{\text {off }}=-0.00002 \cdot H+0.2110 \cdot S V
\end{gathered}
$$

In Method 2, one would use Equations (8) through (13) to determine $A, B$ and $D$ values for any given building based on its specific characteristics $\left(H, S V\right.$ and $\left.F_{\mathrm{n}}\right) . A, B$, and $D$ were calculated for each of the seven reference buildings using these equations and are listed in Table 5 . As was the case with Method 1 (Table 2), the Hospital, Large Office, and Medium Office have negative $A$ values. Using Method 2 , the Small Hotel also had a negative $A$ value. While there are differences between the $A, B$, and $D$ values in Table 2 and Table 5 , the corresponding values are generally on the same order of magnitude. In some cases they are quite close to one another.

Table 5. $A, B$, and $D$ values of simulated buildings using Equations (8) through (13)

$$
\left(I_{\text {design }}=\mathbf{0 . 0 0 1 3 7} \mathrm{m}^{3} / \mathrm{s} \bullet \mathrm{m}^{2}\right)
$$

\begin{tabular}{|l|c|c|c|c|c|c|c|}
\hline & $\begin{array}{c}\text { Full } \\
\text { Service } \\
\text { Restaurant }\end{array}$ & Hospital & $\begin{array}{c}\text { Large } \\
\text { Office }\end{array}$ & $\begin{array}{c}\text { Medium } \\
\text { Office }\end{array}$ & $\begin{array}{c}\text { Primary } \\
\text { School }\end{array}$ & $\begin{array}{c}\text { Small } \\
\text { Hotel }\end{array}$ & $\begin{array}{c}\text { Stand } \\
\text { Alone } \\
\text { Retail }\end{array}$ \\
\hline $\boldsymbol{A}$ on & 0.1424 & -0.0349 & -0.0466 & -0.0082 & 0.0310 & -0.0008 & 0.0137 \\
\hline $\boldsymbol{B}$ on & 0.0186 & 0.0014 & 0.0040 & 0.0036 & 0.0088 & 0.0050 & 0.0059 \\
\hline $\boldsymbol{D}$ on & 0.1004 & 0.0049 & 0.0160 & 0.0177 & 0.0468 & 0.0256 & 0.0311 \\
\hline $\boldsymbol{A}$ off & 0 & NA & 0 & 0 & 0 & NA & 0 \\
\hline $\boldsymbol{B}$ off & 0.0086 & NA & 0.0155 & 0.0106 & 0.0154 & NA & 0.0119 \\
\hline $\boldsymbol{D}$ off & 0.0427 & NA & 0.0175 & 0.0437 & 0.0710 & NA & 0.0515 \\
\hline
\end{tabular}

Note: The Hospital and Small Hotel HVAC systems are always scheduled to be on. 


\section{EVALUATING METHOD 2}

Method 2 is a general approach to improving infiltration calculations in EnergyPlus. In this section, the method is tested using the seven reference buildings and three other buildings, and using different building envelope effective leakage area values, or $I_{\text {design }}$.

\subsection{Evaluation in the seven simulated buildings}

The calculated $A, B$, and $D$ values in Table 5 and $I_{\text {design }}=0.00137 \mathrm{~m}^{3} / \mathrm{s} \cdot \mathrm{m}^{2}$ (referred to as the "original $I_{\text {design }}$ " value since this value is changed in subsequent analyses) were input into the EnergyPlus ZoneInfiltration:DesignFlowRate object for each of the seven reference buildings simulated previously. Annual EnergyPlus simulations were performed using EnergyPlus for the same year of Chicago weather used previously. The calculated hourly infiltration results were then compared between CONTAM and EnergyPlus. The mean of the CONTAM and EnergyPlus infiltration rates are listed in Table 6, along with the standard error, relative standard error, and $R^{2}$ of the EnergyPlus infiltration rates compared with the CONTAM rates. Some $R^{2}$ values in Table 6 are negative because the relationship between the CONTAM and EnergyPlus rates is not linear in these cases. Table 6 shows that, excluding the Hospital and Large Office, the average system-on difference in mean infiltration rates is $18 \%$ and the average system-off difference is $30 \%$. Those two buildings have the smallest mean infiltration rates among the buildings, leading to larger percentage errors. The Medium Office CONTAM and EnergyPlus system-on mean infiltration rates agree within about $1 \%$, and the Large Office CONTAM and EnergyPlus system-off mean infiltration rates differ by only $6 \%$.

Table 6 shows that the Stand Alone Retail and Small Hotel generally have the lowest relative standard errors and highest $R^{2}$ of the buildings. This is also shown in Figure 1, in which the infiltration rates predicted with EnergyPlus are plotted against the rates predicted with CONTAM. Similar plots are presented below as an indication of the relative agreement between the two sets of predictions. Each point corresponds to a single hour in the year, with the uncertainty of each infiltration rate a function of the predictive accuracy of each model. The accuracy of each model is largely a function of the uncertainties in the model inputs. Since these buildings do not exist in reality, there is no uncertainty in the input values. The relative uncertainty in the predictions of the two calculation approaches are captured by the statistics contained in the Table 6 and other similar tables shown below.

Figure 1 shows that the CONTAM and EnergyPlus infiltration rates for the Stand Alone Retail and Small Hotel fall close to lines of perfect agreement. For the Medium Office, Table 6 shows that the system-on relative standard error of the EnergyPlus infiltration rates is among the highest of the buildings, but the $R^{2}$ value is also among the highest. Nevertheless, Figure 2(a) shows good agreement between the CONTAM and EnergyPlus infiltration rates for the Medium Office.

For the Primary School, Table 6 shows that the system-off relative standard error of the EnergyPlus infiltration rates is among the highest of the buildings, and the $R^{2}$ value among the lowest. However, the system-on relative standard error of the EnergyPlus infiltration rates and the $R^{2}$ value are both among the lowest. Figure 2(b) shows the CONTAM versus EnergyPlus infiltration rates for the Primary School. 
For the Full Service Restaurant, Table 6 shows that the system-off relative standard error of the EnergyPlus infiltration rates is comparable with the other buildings though the $R^{2}$ value is the lowest. However, the system-on relative standard error of the EnergyPlus infiltration rates is among the lowest and $R^{2}$ value is among the highest of the buildings. Figure 4 shows good agreement between the CONTAM and EnergyPlus infiltration rates for system-on but not for system-off for the Full Service Restaurant.

For the Large Office, the system-on relative standard error of the EnergyPlus infiltration rates is among the highest of the buildings, and the $R^{2}$ value the lowest. However, the system-off relative standard error of the EnergyPlus infiltration rates is among the lowest and the $R^{2}$ value is among the highest of the buildings. Figure 3(a) shows the CONTAM versus EnergyPlus infiltration rates for the Large Office, where the better agreement with the system off is evident. For the Hospital, the system-on relative standard error of the EnergyPlus infiltration rates is the highest of the buildings and the $R^{2}$ value among the lowest. However, the mean infiltration rate is the lowest of the buildings, which means the absolute standard error is also low. Figure 3(b) shows that the CONTAM rates are underestimated by EnergyPlus for the Hospital.

Table 6. Comparison of CONTAM and EnergyPlus infiltration rates (original $I_{\text {design }}$ )

\begin{tabular}{|c|c|c|c|c|c|c|c|}
\hline & Restaurant & Hospital & $\begin{array}{l}\text { Large } \\
\text { Office }\end{array}$ & $\begin{array}{c}\text { Medium } \\
\text { Office }\end{array}$ & School & Hotel & Retail \\
\hline \multicolumn{8}{|l|}{ System on } \\
\hline $\begin{array}{l}\text { CONTAM mean } \\
\text { infiltration rate }\left(\mathrm{h}^{-1}\right)\end{array}$ & 0.53 & 0.02 & 0.03 & 0.11 & 0.25 & 0.26 & 0.23 \\
\hline $\begin{array}{l}\text { EnergyPlus mean } \\
\text { infiltration rate }\left(\mathrm{h}^{-1}\right)\end{array}$ & 0.46 & 0.01 & 0.08 & 0.11 & 0.34 & 0.19 & 0.21 \\
\hline $\begin{array}{l}\text { Standard error of } \\
\text { EnergyPlus rates }\left(\mathrm{h}^{-1}\right) \\
(\% \text { of CONTAM mean) }\end{array}$ & $\begin{array}{c}0.09 \\
(17 \%)\end{array}$ & $\begin{array}{c}0.02 \\
(130 \%)\end{array}$ & $\begin{array}{c}0.02 \\
(68 \%)\end{array}$ & $\begin{array}{c}0.04 \\
(36 \%)\end{array}$ & $\begin{array}{c}0.07 \\
(26 \%)\end{array}$ & $\begin{array}{c}0.06 \\
(24 \%)\end{array}$ & $\begin{array}{c}0.05 \\
(20 \%)\end{array}$ \\
\hline $\begin{array}{l}\text { Coefficient of } \\
\text { determination, } R^{2}\end{array}$ & 0.80 & -0.23 & -1.74 & 0.83 & 0.31 & 0.61 & 0.83 \\
\hline \multicolumn{8}{|l|}{ System off } \\
\hline $\begin{array}{l}\text { CONTAM mean } \\
\text { infiltration rate }\left(\mathrm{h}^{-1}\right)\end{array}$ & 0.50 & NA & 0.14 & 0.27 & 0.29 & NA & 0.26 \\
\hline $\begin{array}{l}\text { EnergyPlus mean } \\
\text { infiltration rate }\left(\mathrm{h}^{-1}\right)\end{array}$ & 0.15 & NA & 0.13 & 0.23 & 0.44 & NA & 0.29 \\
\hline $\begin{array}{l}\text { Standard error of } \\
\text { EnergyPlus rates }\left(\mathrm{h}^{-1}\right) \\
(\% \text { of CONTAM mean) }\end{array}$ & $\begin{array}{c}0.08 \\
(15 \%) \\
\end{array}$ & NA & $\begin{array}{r}0.02 \\
(16 \%) \\
\end{array}$ & $\begin{array}{c}0.06 \\
(23 \%) \\
\end{array}$ & $\begin{array}{c}0.15 \\
(18 \%) \\
\end{array}$ & NA & $\begin{array}{r}0.03 \\
(13 \%) \\
\end{array}$ \\
\hline $\begin{array}{l}\text { Coefficient of } \\
\text { determination, } R^{2}\end{array}$ & -1.47 & NA & 0.81 & 0.57 & -0.90 & NA & 0.78 \\
\hline
\end{tabular}

Note: The Hospital and Small Hotel HVAC systems are always scheduled to be on. The standard error of EnergyPlus rates and $R^{2}$ values were based on the comparison between EnergyPlus and CONTAM results. 


\section{Stand Alone Retail}

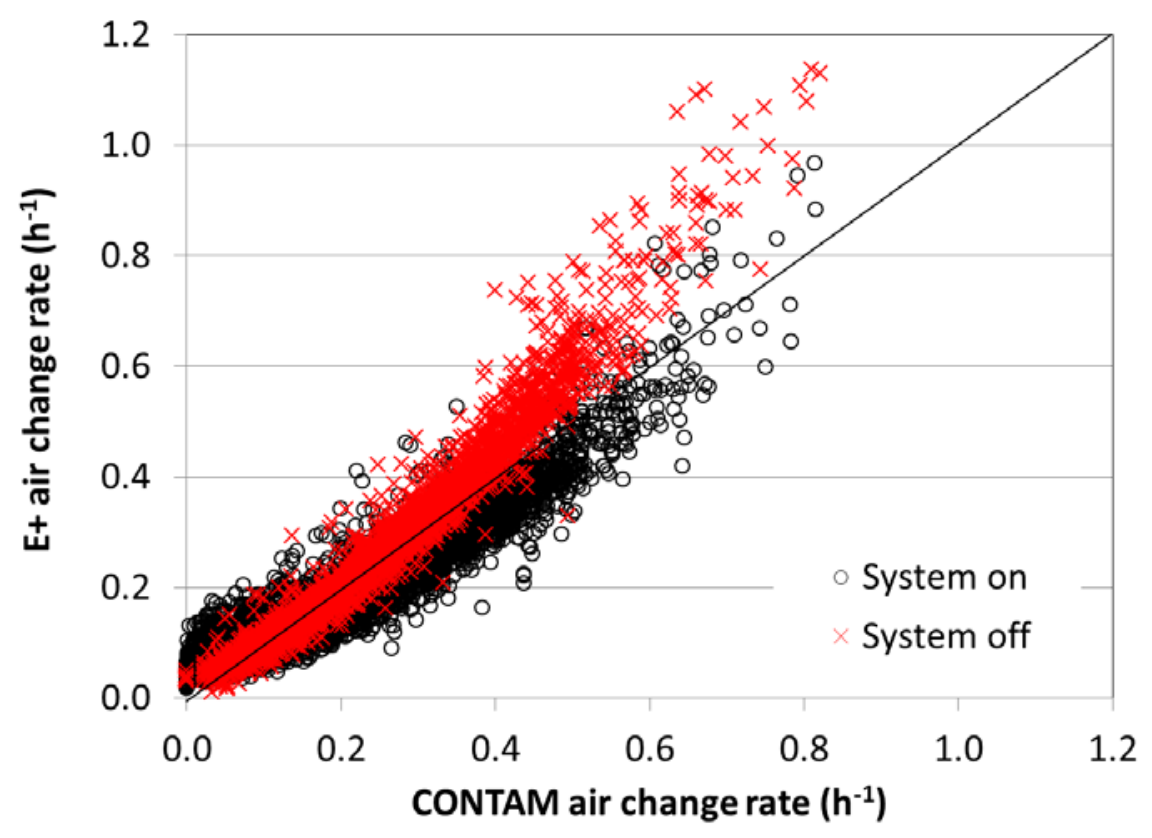

(a)

Small Hotel

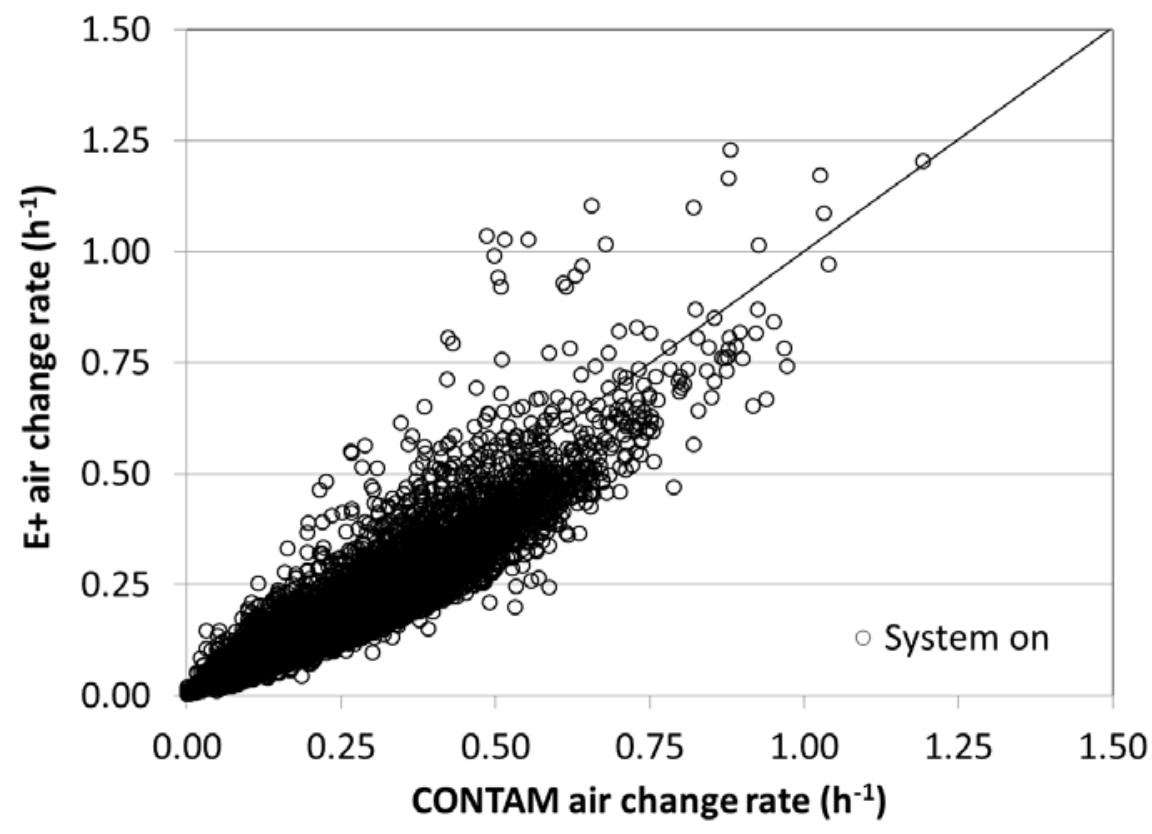

(b)

Figure 1: EnergyPlus vs. CONTAM infiltration rates for (a) Stand Alone Retail and (b) Small Hotel (original $\boldsymbol{I}_{\text {design}}$ ) 


\section{Medium Office}

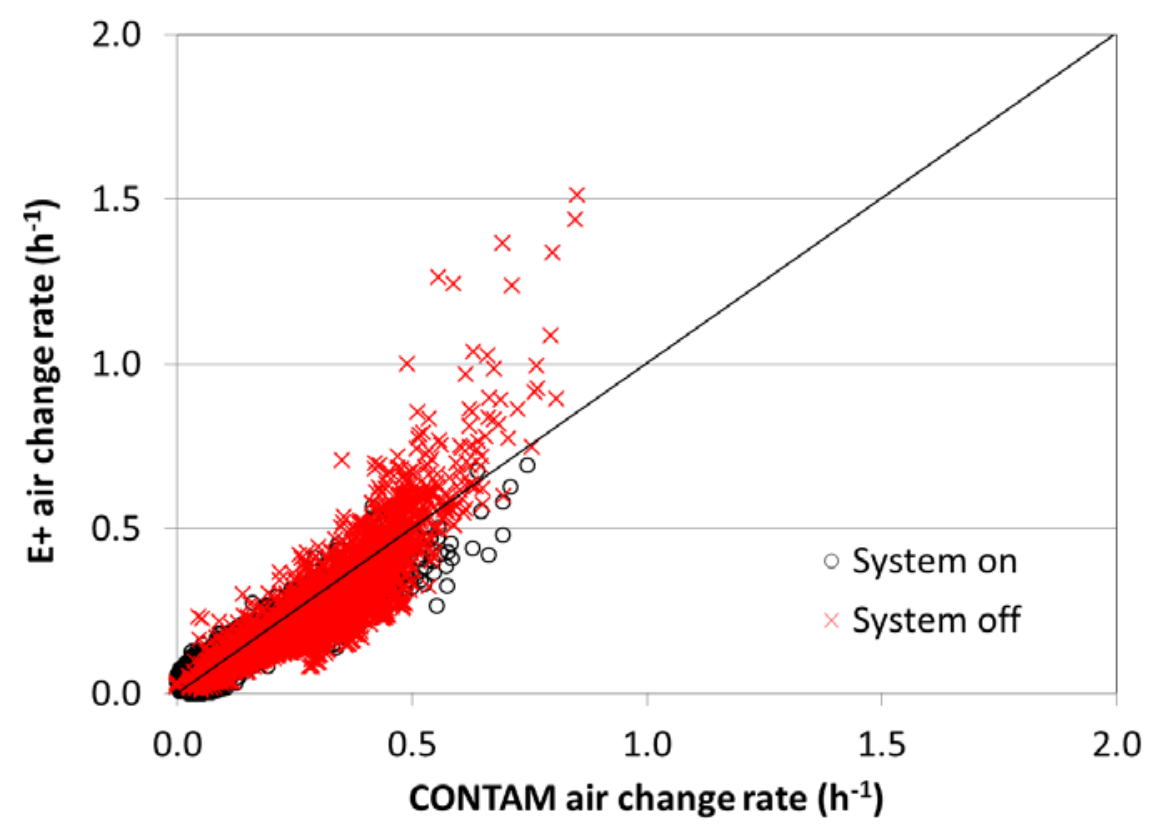

(a)

\section{Primary School}

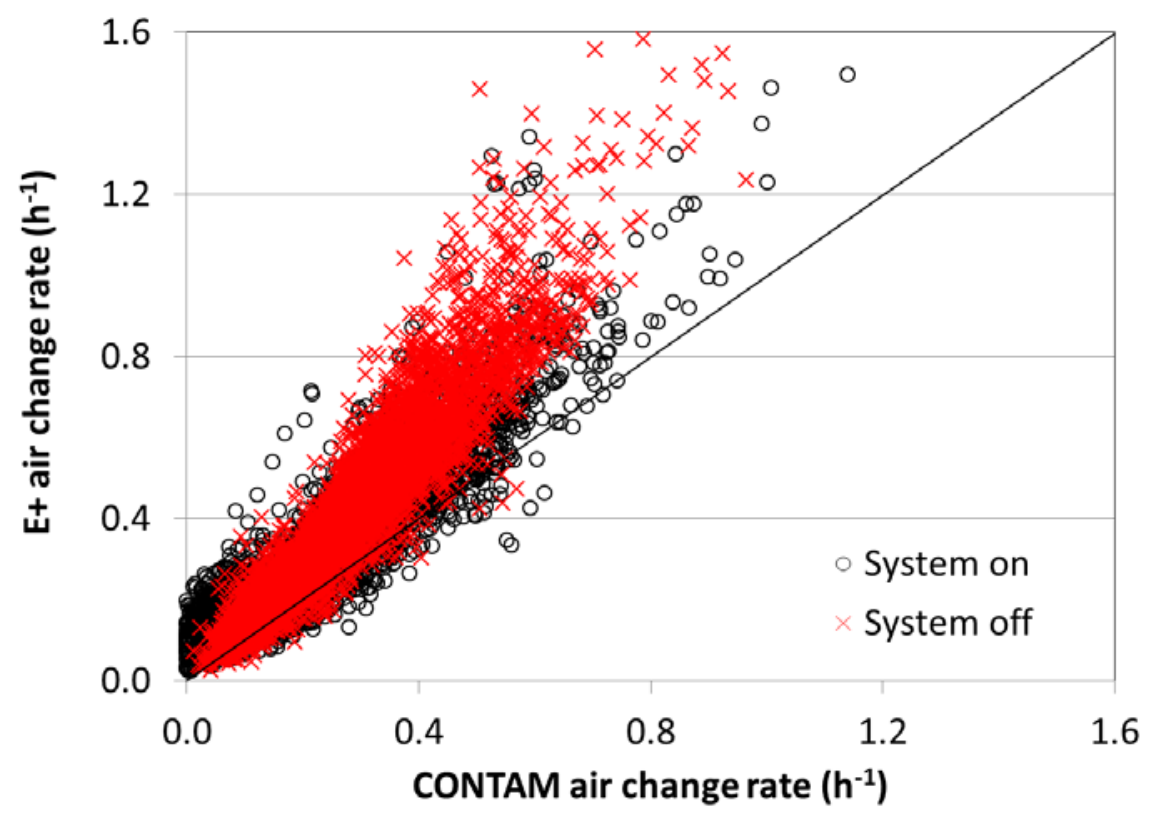

(b)

Figure 2: EnergyPlus vs. CONTAM infiltration rates for (a) Medium Office and

(b) Primary School (original $\boldsymbol{I}_{\text {design}}$ ) 


\section{Large Office}

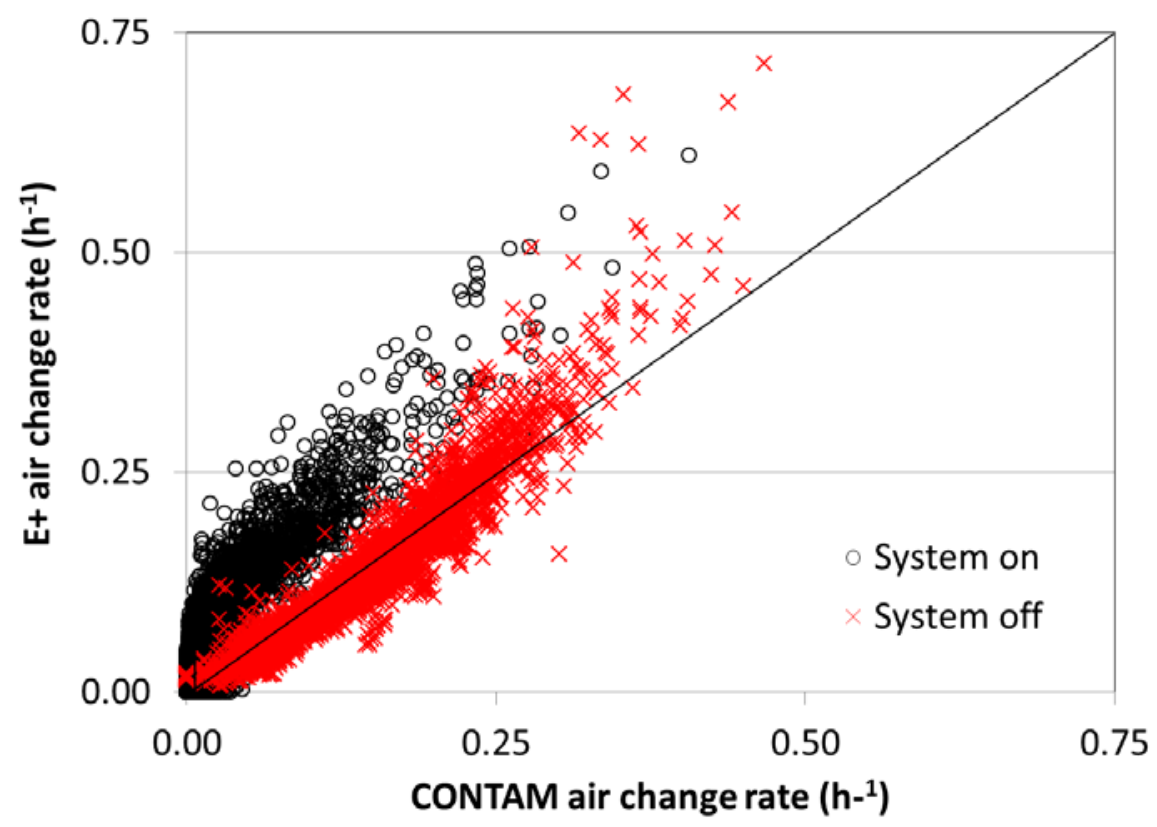

(a)

\section{Hospital}

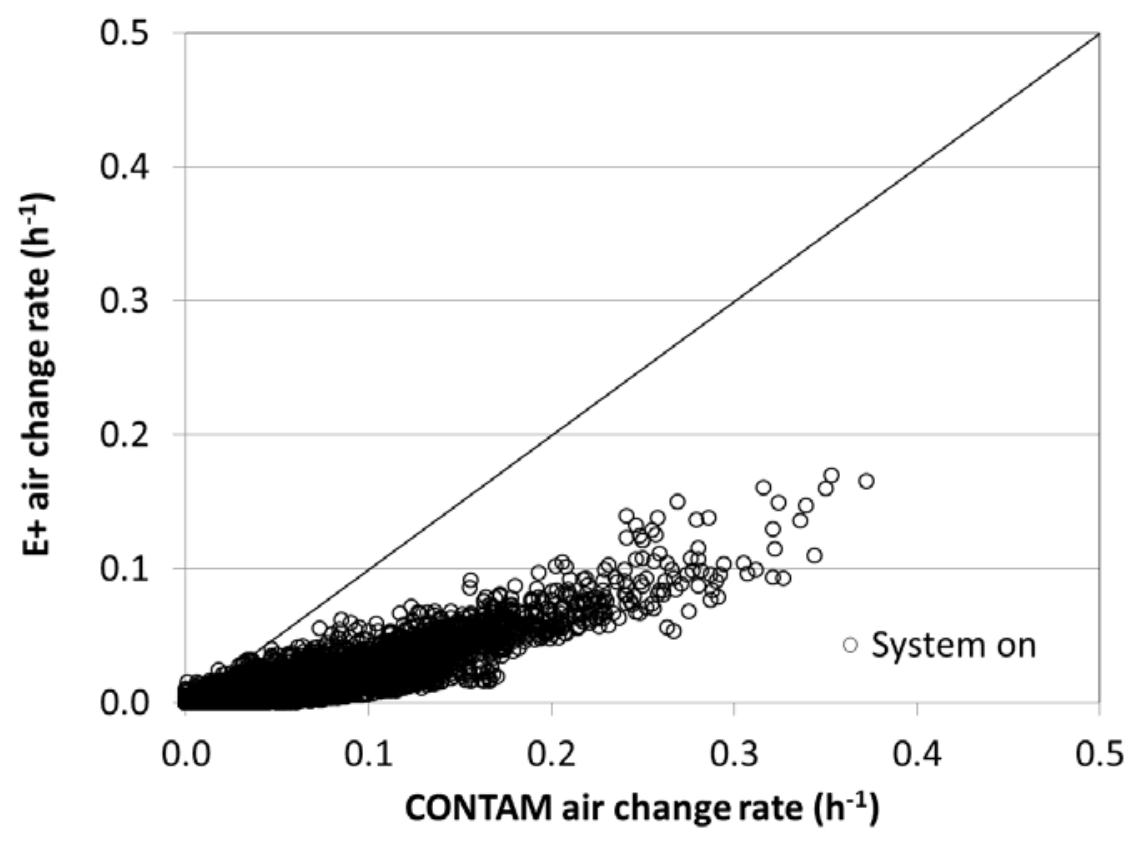

(b)

Figure 3: EnergyPlus vs. CONTAM infiltration rates for (a) Large Office and (b) Hospital (original $I_{\text {design}}$ ) 


\section{Full Service Restaurant}

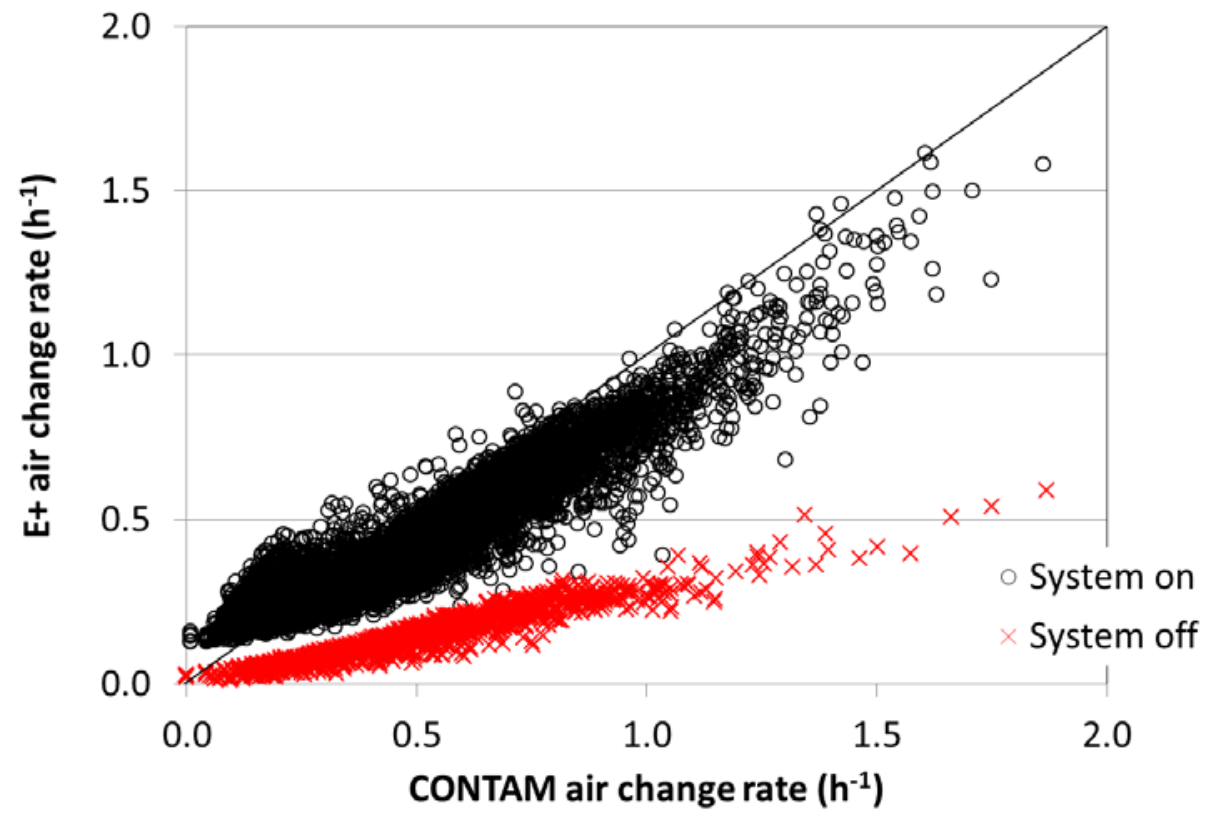

Figure 4: EnergyPlus vs. CONTAM infiltration rates for Full Service Restaurant (original $I_{\text {design}}$ )

In general, buildings with the lowest infiltration rates, the Hospital and two offices, also have the highest system-on relative standard errors. However, since the absolute infiltration rates are relatively low for these three buildings, the absolute errors in the infiltration rates are also low. Thus, despite high relative standard errors, Figure 2 and Figure 3 show good agreement between CONTAM and EnergyPlus rates for the Hospital and two offices. For all of the buildings except the Hospital and Full Service Restaurant, there is good agreement between the system-on and system-off infiltration rates calculated by CONTAM and EnergyPlus as shown in Figure 1 through Figure 4. Though the average system-on and system-off $R^{2}$ values for the seven buildings is only 0.08 , the average system-on relative standard error, excluding the Hospital and Large Office, is $25 \%$ and the average system-off relative standard error is $17 \%$. Note that these analyses are based on the original value of $I_{\text {design. }}$. Additional simulations are discussed below in which this value is varied.

\subsection{Evaluation of Method 2 in other buildings}

Method 2, as embodied in Equations (8) to (13), was used to calculate system-on and system-off $A, B$, and $D$ values (not shown) for three additional buildings based only on their building characteristics. The buildings were the Small Office building from the DOE reference buildings, and two actual buildings on the NIST campus, the Administration and the TRF Buildings. The building height, exterior surface area to volume ratio, and net system flow normalized by exterior surface area for these buildings are listed in Table 7. The height and surface area to volume ratio of the Small Office is similar to the Full Service Restaurant, and its normalized net system flow is similar to the Medium Office. For more details on the Small Office, see Ng et al. (2012). The NIST Administration Building is almost as tall as the Large Office, has the smallest surface to 
volume ratio and largest normalized net system flow of the buildings considered in this paper. The height and surface area to volume ratio of the NIST TRF Building is similar to the Primary School, and its normalized net system flow is similar to the Small Hotel. For more details on the NIST buildings, see Persily et al. (2007).

Table 7. Building characteristics of three additional buildings

\begin{tabular}{|l|c|c|c|}
\hline & $\begin{array}{c}\text { Small } \\
\text { Office }\end{array}$ & $\begin{array}{c}\text { NIST } \\
\text { Administration }\end{array}$ & $\begin{array}{c}\text { NIST } \\
\text { TRF }\end{array}$ \\
\hline $\boldsymbol{H} \mathbf{( m )}$ & 4.3 & 46.6 & 4.0 \\
\hline $\boldsymbol{S} V\left(\mathbf{m}^{2} / \mathbf{m}^{3}\right)$ & 0.18 & 0.05 & 0.36 \\
\hline $\boldsymbol{F}_{\mathbf{n}}\left(\mathbf{m}^{\mathbf{3}} / \mathbf{s}^{\cdot} \mathbf{m}^{\mathbf{2}}\right) \times \mathbf{1 0}^{-3}$ & 0.61 & 0.85 & 0.51 \\
\hline
\end{tabular}

The average local wind speed adjustments for the Small Office and two NIST buildings are listed in Table 8. An EnergyPlus model was available for the Small Office (DOE 2011), but not for the two NIST buildings. Thus, rather than using EnergyPlus, infiltration rates for the NIST buildings were calculated using a spreadsheet that implemented Equation (1) with $C=0$, where $W_{\mathrm{s}}$ was calculated using Equation (4) and the wind speed adjustments listed in Table 8.

Table 8. Average local wind speed adjustments (other buildings)

\begin{tabular}{|l|c|}
\hline Building & Average Local Wind Speed Adjustment \\
\hline Small Office & 0.2818 \\
\hline NIST Administration Building & 0.4650 \\
\hline NIST TRF Building & 0.2784 \\
\hline
\end{tabular}

For the Small Office, Table 9 shows that the system-on relative standard error of the EnergyPlus infiltration rates is one of the highest and the $R^{2}$ value the lowest relative to the seven other reference buildings in Table 6 . The system-off relative standard error and $R^{2}$ value of the EnergyPlus infiltration rates are both low compared to the other seven buildings. Figure 5 shows that EnergyPlus underestimates the infiltration rates when compared to CONTAM for the Small Office for both system-on and system-off conditions. As in the case of the Full Service Restaurant, the Small Office has an attic space that may contribute to the low infiltration estimates.

For the NIST Administration Building, Table 9 shows that the system-on relative standard error of the calculated infiltration rates are in the middle of the range seen in the seven reference buildings in Table 6 , but the $R^{2}$ value is one of the lowest. The system-off relative standard error of the calculated infiltration rates is among the lowest and the $R^{2}$ value lower than all seven buildings (Table 6). Figure 6(a) shows that the calculated infiltration rates are lower than the values calculated by CONTAM for the Administration Building.

For the NIST TRF Building, Table 9 shows that the system-on relative standard error of the calculated infiltration rates is also in the middle of the range seen in the seven buildings in Table 6 , but the $R^{2}$ value is one of the highest. Both the system-off relative standard error of the calculated infiltration rates and the $R^{2}$ value are among the lowest relative to the seven buildings. Nevertheless, Figure 6 (b) shows good agreement between the calculated and CONTAM infiltration rates for the NIST TRF Building. 
Table 9. Comparison of CONTAM and EnergyPlus and calculated infiltration rates

\begin{tabular}{|c|c|c|c|}
\hline & Small Office & $\begin{array}{c}\text { NIST } \\
\text { Administration }^{1}\end{array}$ & $\begin{array}{l}\text { NIST } \\
\text { TRF }^{1}\end{array}$ \\
\hline \multicolumn{4}{|l|}{ System on } \\
\hline $\begin{array}{l}\text { CONTAM mean } \\
\text { infiltration rate }\left(\mathrm{h}^{-1}\right)\end{array}$ & 0.33 & 0.17 & 0.29 \\
\hline $\begin{array}{l}\text { EnergyPlus or calculated mean } \\
\text { infiltration rate }\left(\mathrm{h}^{-1}\right)\end{array}$ & 0.02 & 0.04 & 0.29 \\
\hline $\begin{array}{l}\text { Standard error of } \\
\text { EnergyPlus rates or calculated rates }\left(\mathrm{h}^{-1}\right) \\
\text { (\% of CONTAM mean) }\end{array}$ & $\begin{array}{c}0.08 \\
(23 \%)\end{array}$ & $\begin{array}{c}0.05 \\
(33 \%)\end{array}$ & $\begin{array}{c}0.09 \\
(30 \%)\end{array}$ \\
\hline Coefficient of determination, $R^{2}$ & -2.59 & -0.67 & 0.82 \\
\hline \multicolumn{4}{|l|}{ System off } \\
\hline $\begin{array}{l}\text { CONTAM mean } \\
\text { infiltration rate }\left(\mathrm{h}^{-1}\right)\end{array}$ & 0.37 & 0.34 & 0.43 \\
\hline $\begin{array}{l}\text { EnergyPlus or calculated mean } \\
\text { infiltration rate }\left(\mathrm{h}^{-1}\right)\end{array}$ & 0.13 & 0.05 & 0.59 \\
\hline $\begin{array}{l}\text { Standard error of } \\
\text { EnergyPlus or calculated rates }\left(\mathrm{h}^{-1}\right) \\
\text { (\% of CONTAM mean) }\end{array}$ & $\begin{array}{c}0.06 \\
(17 \%)\end{array}$ & $\begin{array}{c}0.05 \\
(14 \%)\end{array}$ & $\begin{array}{c}0.08 \\
(18 \%)\end{array}$ \\
\hline Coefficient of determination, $R^{2}$ & -1.30 & -3.06 & -0.05 \\
\hline
\end{tabular}

\section{Small Office}

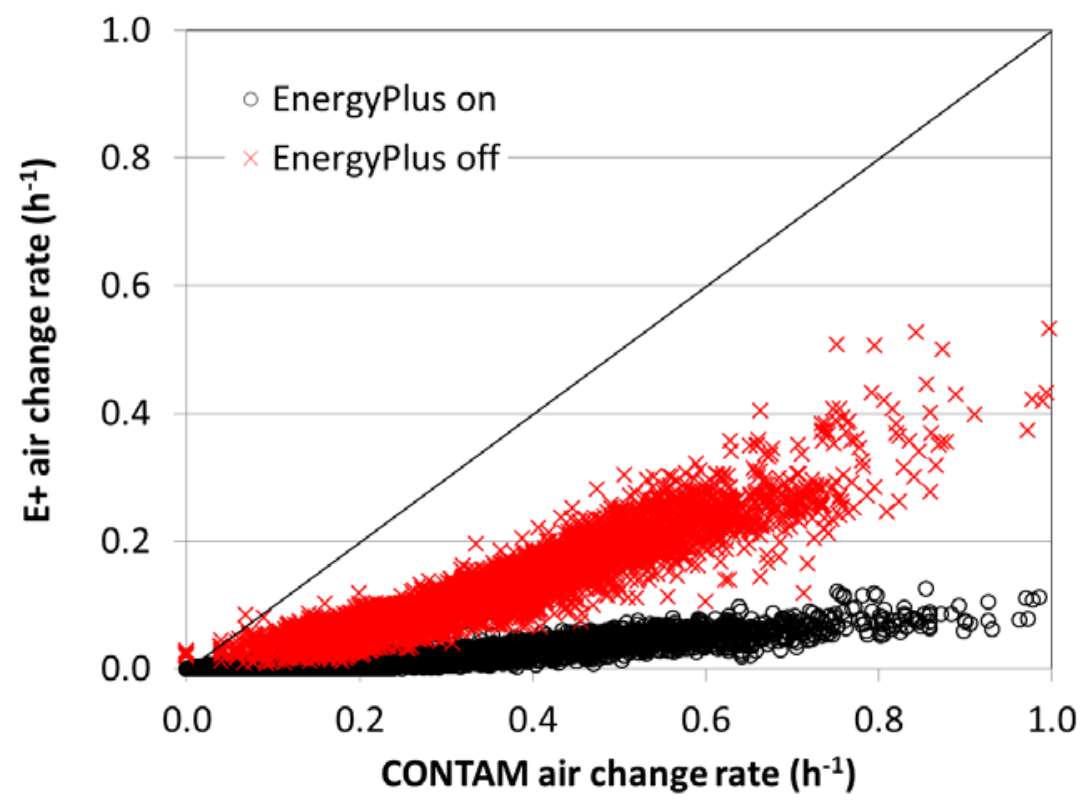

Figure 5: EnergyPlus vs. CONTAM infiltration rates for Small Office (original $I_{\text {design }}$ ) 
NIST Admin BIdg

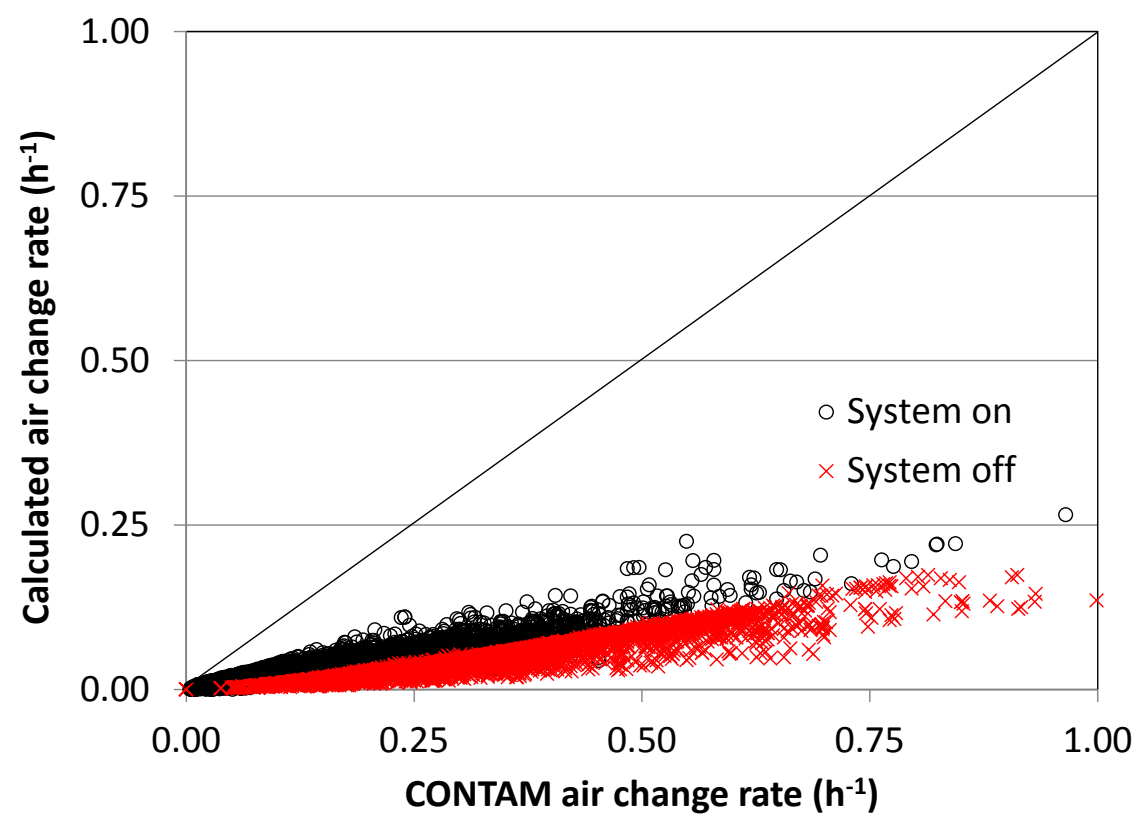

(a)

NIST TRF BIdg

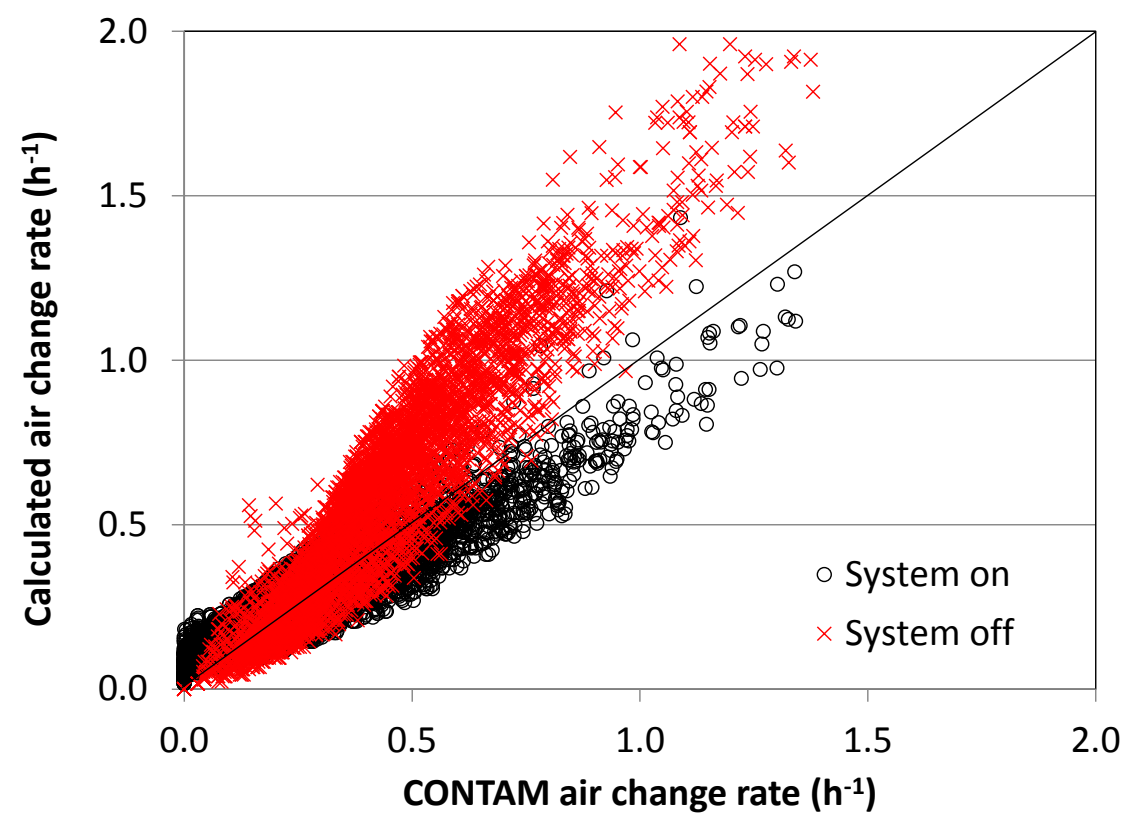

(b)

Figure 6: Calculated vs. CONTAM infiltration rates for (a) NIST Administration Building and (b) NIST TRF Building 
As noted earlier, EnergyPlus models were not available for the NIST buildings, thus, infiltration was calculated using a spreadsheet and may not reflect the rates that EnergyPlus would calculate. This is due to the fact that EnergyPlus applies a different wind speed adjustment to each zone depending on its height. In contrast, the infiltration calculated by the spreadsheet uses a single average local wind speed adjustment for the entire building (Table 8). This could explain the underestimated infiltration rates in the NIST Administration Building, which was one of the taller buildings. Using an average local wind speed adjustment may neglect the impacts of wind on infiltration on the highest floors.

\subsection{Evaluation of Method 2 for other $I_{\text {design }}$ values}

Additional analyses were performed to investigate how well Method 2 performed for different envelope airtightness values than that used to derive Equations (8) through (13). As noted above, these equations were developed using a building envelope effective leakage area of $5.27 \mathrm{~cm}^{2} / \mathrm{m}^{2}$ at $4 \mathrm{~Pa}$ (i.e., $I_{\text {design }}=0.00137 \mathrm{~m}^{3} / \mathrm{s}^{\bullet} \mathrm{m}^{2}$, referred to as "original $I_{\text {design }}$ "). Method 2 was applied using two other $I_{\text {design }}$ values by running both CONTAM and EnergyPlus simulations with these new values. CONTAM simulations were re-run with building envelope effective leakage areas of $1.18 \mathrm{~cm}^{2} / \mathrm{m}^{2}$ at $4 \mathrm{~Pa}$ and $20.96 \mathrm{~cm}^{2} / \mathrm{m}^{2}$ at $4 \mathrm{~Pa}$, which were respectively four times lower and four times higher than the original $I_{\text {design }}$ value. EnergyPlus simulations were re-run with corresponding $I_{\text {design }}$ values of $0.000304 \mathrm{~m}^{3} / \mathrm{s} \bullet \mathrm{m}^{2}$ (or "low $I_{\text {design }}$ ) and $0.0054 \mathrm{~m}^{3} / \mathrm{s}^{\bullet} \mathrm{m}^{2}$ (or "high $I_{\text {design }}$ ") respectively. In these EnergyPlus simulations, the $I_{\text {design }}$ values changed, but the $A, B$, and $D$ values remained the same as those determined using the original $I_{\text {design }}$ value, shown in Table 5. The calculated hourly infiltration rates were then compared between CONTAM and EnergyPlus.

As was the case for the original $I_{\text {design }}$ value, Table 10 shows that the Stand Alone Retail and Small Hotel generally have the lowest relative standard errors and highest $R^{2}$ of the buildings for both system-on and system-off conditions with the low $I_{\text {design }}$ value. The relative standard errors of the EnergyPlus infiltration rates using the low $I_{\text {design }}$ value are higher than they were using the original $I_{\text {design }}$ value (Table 6 ), and the system-on $R^{2}$ value for the Stand Alone Retail is lower. Nevertheless, Figure 7(a) and (b) show that the CONTAM versus EnergyPlus infiltration rates fall close to lines of perfect agreement for the Stand Alone Retail and Small Hotel.

For all of the remaining buildings, either or both the system-on and system-off $R^{2}$ values are negative for the low $I_{\text {design }}$ value. The system-off relative standard errors of the EnergyPlus infiltration rates using the low $I_{\text {design }}$ value are comparable to those using the original $I_{\text {design }}$ value (Table 6), but the system-on relative standard errors are higher, with the exception of the Full Service Restaurant. Table 10 shows that the buildings with positive $R^{2}$ values are the Medium Office with system off, Full Service Restaurant with system on, and Large Office with systemoff. Figure 8(a) and Figure 9(a) show that for the Medium Office and Large Office, the systemoff EnergyPlus rates agree well with CONTAM, but the system-on rates are overestimated by EnergyPlus. In contrast, Figure 8(b) shows that for the Full Service Restaurant, the system-on EnergyPlus rates agree well with CONTAM, but the system-off rates are underestimated by EnergyPlus. 
Table 10. Comparison of CONTAM and EnergyPlus infiltration rates (low $\boldsymbol{I}_{\text {design }}$ )

\begin{tabular}{|c|c|c|c|c|c|c|c|c|}
\hline & Restaurant & Hospital & $\begin{array}{l}\text { Large } \\
\text { Office }\end{array}$ & $\begin{array}{l}\text { Medium } \\
\text { Office }\end{array}$ & $\begin{array}{l}\text { Small } \\
\text { Office }\end{array}$ & School & Hotel & Retail \\
\hline \multicolumn{9}{|l|}{ System on } \\
\hline $\begin{array}{l}\text { CONTAM mean } \\
\text { infiltration rate }\left(\mathrm{h}^{-1}\right)\end{array}$ & 0.12 & 0.0001 & 0.00003 & 0.002 & 0.05 & 0.02 & 0.03 & 0.03 \\
\hline $\begin{array}{l}\text { EnergyPlus mean } \\
\text { infiltration rate }\left(\mathrm{h}^{-1}\right)\end{array}$ & 0.10 & 0.0023 & 0.02 & 0.03 & 0.01 & 0.08 & 0.04 & 0.05 \\
\hline $\begin{array}{l}\text { Standard error of } \\
\text { EnergyPlus rates }\left(\mathrm{h}^{-1}\right) \\
(\% \text { of CONTAM mean) }\end{array}$ & $\begin{array}{c}0.02 \\
(17 \%)\end{array}$ & $\begin{array}{l}0.0006 \\
(720 \%)\end{array}$ & $\begin{array}{l}0.0003 \\
(881 \%)\end{array}$ & $\begin{array}{c}0.01 \\
(258 \%)\end{array}$ & $\begin{array}{c}0.02 \\
(40 \%)\end{array}$ & $\begin{array}{c}0.01 \\
(60 \%)\end{array}$ & $\begin{array}{c}0.01 \\
(34 \%)\end{array}$ & $\begin{array}{c}0.01 \\
(35 \%)\end{array}$ \\
\hline $\begin{array}{l}\text { Coefficient of } \\
\text { determination, } R^{2}\end{array}$ & 0.78 & -23 & -5880 & -11 & -1.08 & -3 & 0.66 & 0.29 \\
\hline \multicolumn{9}{|l|}{ System off } \\
\hline $\begin{array}{l}\text { CONTAM mean } \\
\text { infiltration rate }\left(\mathrm{h}^{-1}\right)\end{array}$ & 0.11 & NA & 0.03 & 0.06 & 0.08 & 0.07 & NA & 0.06 \\
\hline $\begin{array}{l}\text { EnergyPlus mean } \\
\text { infiltration rate }\left(\mathrm{h}^{-1}\right)\end{array}$ & 0.03 & NA & 0.03 & 0.05 & 0.03 & 0.11 & NA & 0.07 \\
\hline $\begin{array}{l}\text { Standard error of } \\
\text { EnergyPlus rates }\left(\mathrm{h}^{-1}\right) \\
\text { (\% of CONTAM mean) }\end{array}$ & $\begin{array}{c}0.02 \\
(16 \%)\end{array}$ & NA & $\begin{array}{c}0.00 \\
(15 \%)\end{array}$ & $\begin{array}{c}0.01 \\
(22 \%)\end{array}$ & $\begin{array}{c}0.01 \\
(17 \%)\end{array}$ & $\begin{array}{c}0.01 \\
(18 \%)\end{array}$ & NA & $\begin{array}{c}0.01 \\
(12 \%)\end{array}$ \\
\hline $\begin{array}{l}\text { Coefficient of } \\
\text { determination, } R^{2}\end{array}$ & -1.44 & NA & 0.81 & 0.63 & -1.26 & -1.88 & NA & 0.68 \\
\hline
\end{tabular}

Note: The Hospital and Small Hotel HVAC systems are always scheduled to be on. The standard error of EnergyPlus rates and $R^{2}$ values were based on the comparison between EnergyPlus and CONTAM results.

Table 10 shows that the buildings with negative $R^{2}$ values for both system-on and system-off conditions using the low $I_{\text {design }}$ value are the Small Office, Primary School, and Hospital. Figure 9(b) shows that for the Small Office, both the system-on and system-off rates are underestimated by EnergyPlus. In contrast, Figure 10(a) and (b) show that for the Primary School and Hospital, the rates are overestimated by EnergyPlus.

The summary statistics using the high $I_{\text {design }}$ value in Table 11 show that the relative standard errors of EnergyPlus infiltration rates are not as high as for the low $I_{\text {design }}$ value (Table 10). While there are still a few cases where the $R^{2}$ value is negative, they are not as low as the values in Table 10. Similarly, the summary statistics in Table 11 are sometimes better than those seen in Table 6 for the original $I_{\text {design }}$ value.

As was the case for the original and low $I_{\text {design }}$ values, Table 11 shows that the Stand Alone Retail and Small Hotel generally have the lowest relative standard errors and highest $R^{2}$ of the buildings for the high $I_{\text {design }}$ value. The Large Office also has relative standard errors among the lowest and $R^{2}$ values among the highest of the buildings listed in Table 11 for the high $I_{\text {design }}$ value. The statistical measures for the Large Office for the high $I_{\text {design }}$ value were much better than those with the original and low $I_{\text {design }}$ values. Figure 11(a) and (b) and Figure 12 show that the CONTAM versus EnergyPlus infiltration rates fall close to lines of perfect agreement for the Stand Alone Retail, Small Hotel, and Large Office.

For the remaining buildings, Table 11 shows that the buildings with all positive $R^{2}$ values are the Primary School and Medium Office. From Figure 12(b) and Figure 13(a), shows good agreement between CONTAM and EnergyPlus rates for the Primary School and Medium Office. 
Table 11. Comparison of CONTAM and EnergyPlus infiltration results (high $\boldsymbol{I}_{\text {design }}$ )

\begin{tabular}{|c|c|c|c|c|c|c|c|c|}
\hline & Restaurant & Hospital & $\begin{array}{l}\text { Large } \\
\text { Office }\end{array}$ & $\begin{array}{l}\text { Medium } \\
\text { Office }\end{array}$ & $\begin{array}{l}\text { Small } \\
\text { Office }\end{array}$ & School & Hotel & Retail \\
\hline \multicolumn{9}{|l|}{ System on } \\
\hline $\begin{array}{l}\text { CONTAM mean } \\
\text { infiltration rate }\left(\mathrm{h}^{-1}\right)\end{array}$ & 2.05 & 0.51 & 0.36 & 0.77 & 1.38 & 1.14 & 1.21 & 1.04 \\
\hline $\begin{array}{l}\text { EnergyPlus mean } \\
\text { infiltration rate }\left(\mathrm{h}^{-1}\right)\end{array}$ & 1.82 & 0.04 & 0.30 & 0.43 & 0.10 & 1.35 & 0.77 & 0.82 \\
\hline $\begin{array}{l}\text { Standard error of } \\
\text { EnergyPlus rates }\left(\mathrm{h}^{-1}\right) \\
(\% \text { of CONTAM mean) }\end{array}$ & $\begin{array}{c}0.35 \\
(17 \%) \\
\end{array}$ & $\begin{array}{c}0.19 \\
(37 \%) \\
\end{array}$ & $\begin{array}{c}0.08 \\
(23 \%) \\
\end{array}$ & $\begin{array}{c}0.17 \\
(22 \%) \\
\end{array}$ & $\begin{array}{c}0.26 \\
(19 \%) \\
\end{array}$ & $\begin{array}{c}0.27 \\
(24 \%) \\
\end{array}$ & $\begin{array}{c}0.27 \\
(23 \%) \\
\end{array}$ & $\begin{array}{c}0.20 \\
(19 \%) \\
\end{array}$ \\
\hline $\begin{array}{l}\text { Coefficient of } \\
\text { determination, } R^{2}\end{array}$ & 0.81 & -2.18 & 0.78 & 0.26 & -3.51 & 0.60 & 0.27 & 0.70 \\
\hline \multicolumn{9}{|l|}{ System off } \\
\hline $\begin{array}{l}\text { CONTAM mean } \\
\text { infiltration rate }\left(\mathrm{h}^{-1}\right)\end{array}$ & 1.95 & NA & 0.53 & 1.01 & 1.39 & 1.16 & NA & 1.04 \\
\hline $\begin{array}{l}\text { EnergyPlus mean } \\
\text { infiltration rate }\left(\mathrm{h}^{-1}\right)\end{array}$ & 0.54 & NA & 0.47 & 0.80 & 0.49 & 1.45 & NA & 1.00 \\
\hline $\begin{array}{l}\text { Standard error of } \\
\text { EnergyPlus rates }\left(\mathrm{h}^{-1}\right) \\
\text { (\% of CONTAM mean) }\end{array}$ & $\begin{array}{c}0.29 \\
(15 \%)\end{array}$ & NA & $\begin{array}{c}0.09 \\
(17 \%)\end{array}$ & $\begin{array}{c}0.25 \\
(25 \%)\end{array}$ & $\begin{array}{c}0.24 \\
(17 \%)\end{array}$ & $\begin{array}{c}0.22 \\
(19 \%)\end{array}$ & NA & $\begin{array}{c}0.16 \\
(15 \%)\end{array}$ \\
\hline $\begin{array}{l}\text { Coefficient of } \\
\text { determination, } R^{2}\end{array}$ & -1.59 & NA & 0.77 & 0.45 & -1.45 & 0.26 & NA & 0.86 \\
\hline
\end{tabular}

Note: The Hospital and Small Hotel HVAC systems are always scheduled to be on. The standard error of EnergyPlus rates and $R^{2}$ values were based on the comparison between EnergyPlus and CONTAM results.

Table 11 shows that the Full Service Restaurant has only one negative $R^{2}$ value using the high $I_{\text {design }}$ value. Nevertheless, the system-on EnergyPlus rates are in good agreement with CONTAM as shown in Figure 13(b). The Hospital and Small Office have all negative $R^{2}$ values. Figure 14(a) and (b) show that the CONTAM rates are underestimated by EnergyPlus for the Hospital and Small Office. The relative standard error of the EnergyPlus rates is higher in the Hospital than in the Small Office because its infiltration rates are lower.

As seen in Table 10 and Figure 7 through Figure 10, using a value of $I_{\text {design }}$ that is one-quarter of the value used to develop Method 2 resulted in comparable agreement between the EnergyPlus and CONTAM infiltration rates in most buildings tested. The exceptions were the Large and Small Offices, Primary School, and Hospital. The level of agreement between CONTAM and EnergyPlus infiltration rates is better using the high $I_{\text {design }}$ value (Table 11 and Figure 11 through Figure 14) relative to using the low $I_{\text {design }}$ value for the buildings tested test cases in this paper. No studies using different $I_{\text {design }}$ values for the NIST buildings were performed because EnergyPlus models were not available to make those comparisons. These results show that as Method 2 is developed further, it will be important to identify a range of $I_{\text {design }}$ values over which it can be applied without introducing excessive errors. 


\section{Stand Alone Retail}

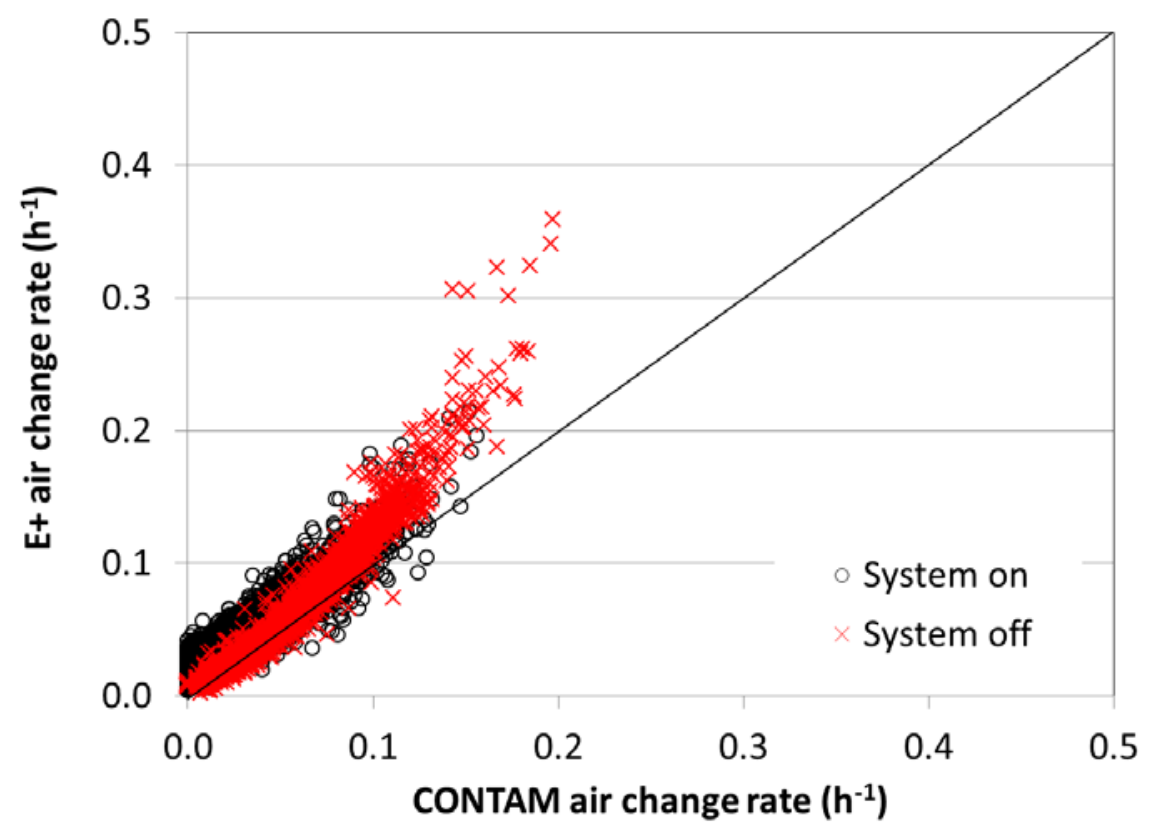

(a)

Small Hotel

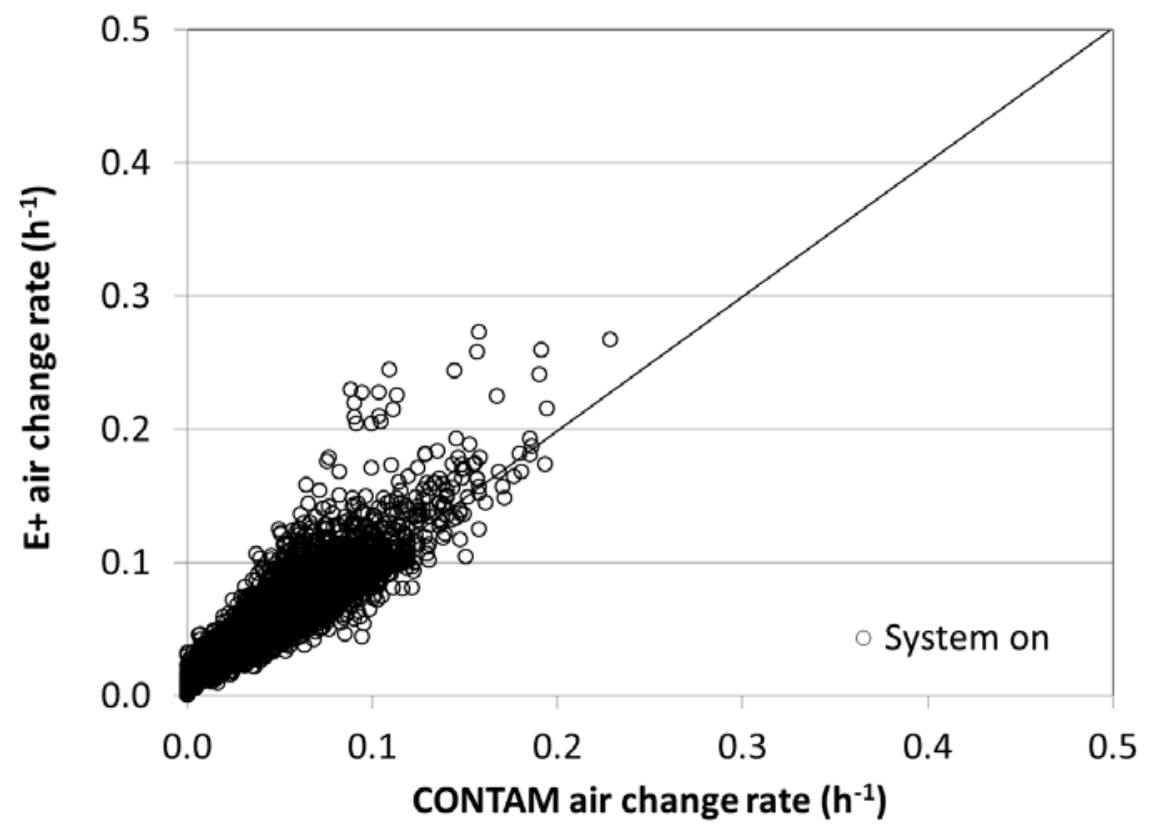

(b)

Figure 7: EnergyPlus vs. CONTAM infiltration rates for (a) Stand Alone Retail and

(b) Small Hotel (low $I_{\text {design}}$ ) 


\section{Medium Office}

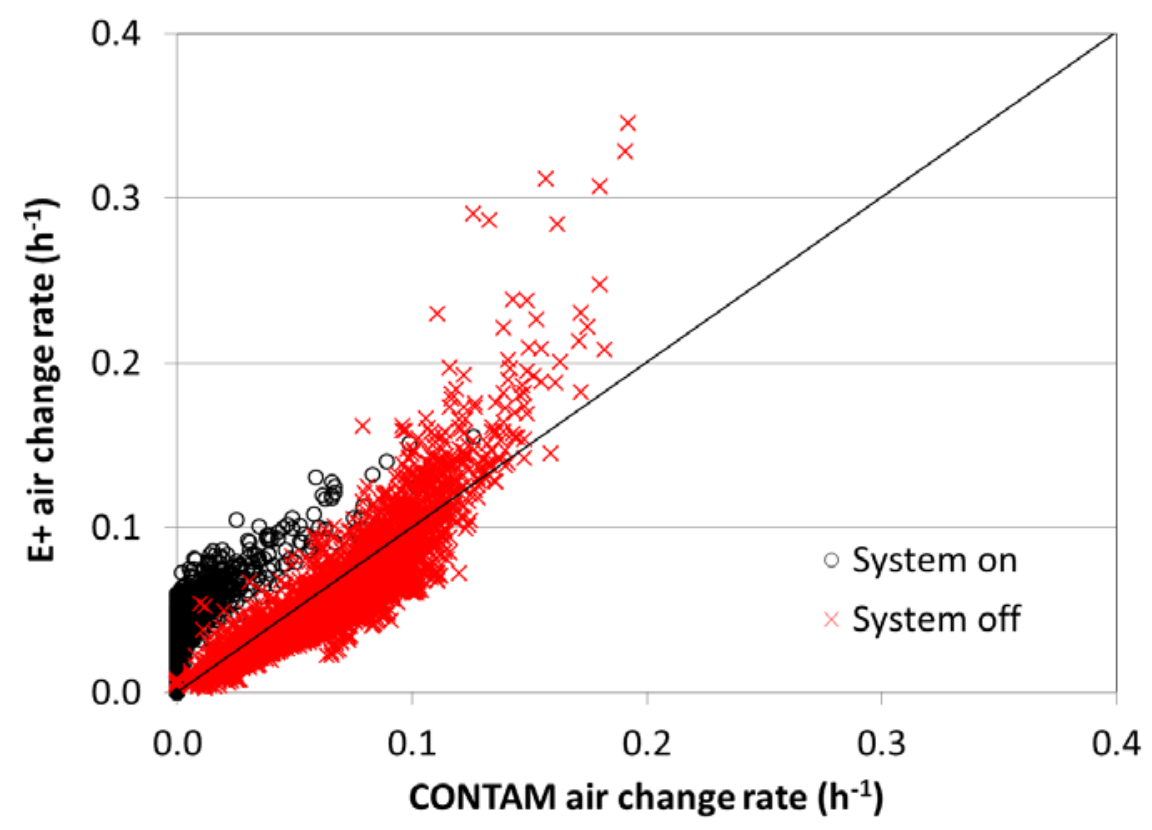

(a)

\section{Full Service Restaurant}

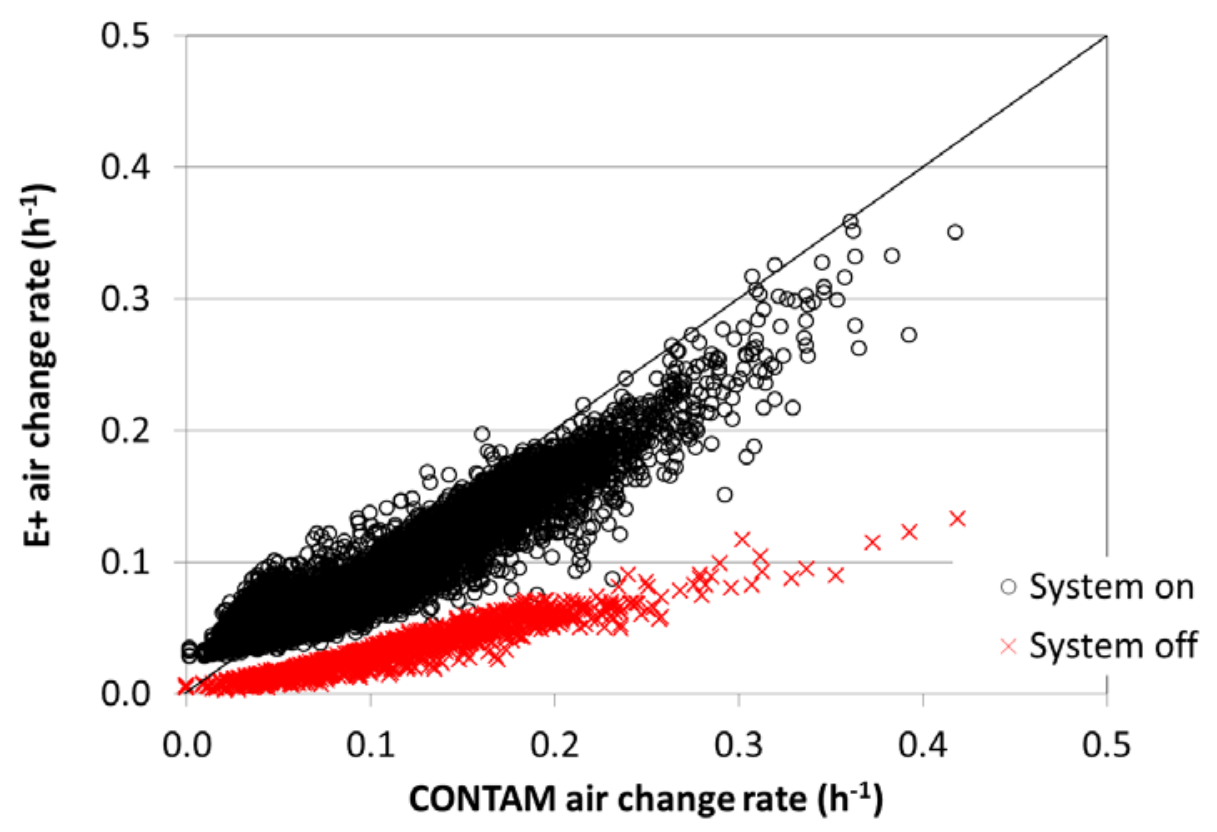

(b)

Figure 8: EnergyPlus vs. CONTAM infiltration rates for (a) Medium Office and (b) Full Service Restaurant (low $I_{\text {design}}$ ) 


\section{Large Office}

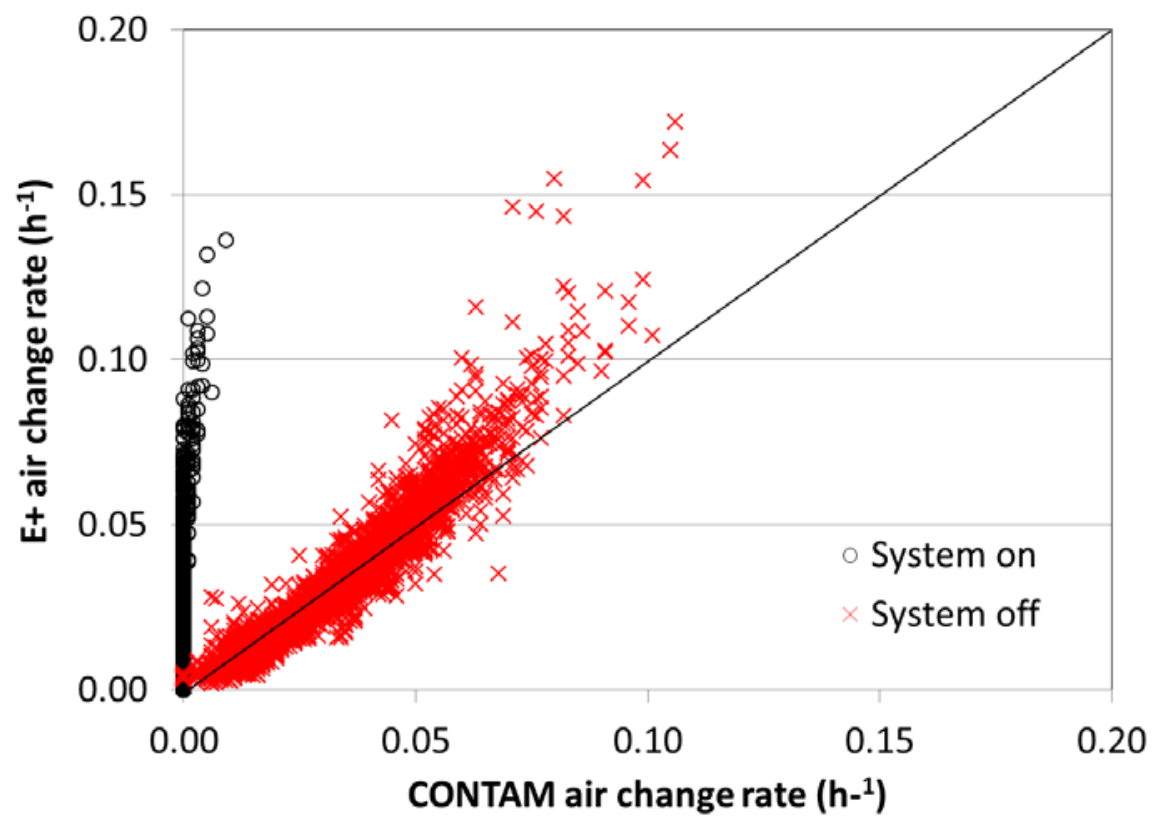

(a)

\section{Small Office}

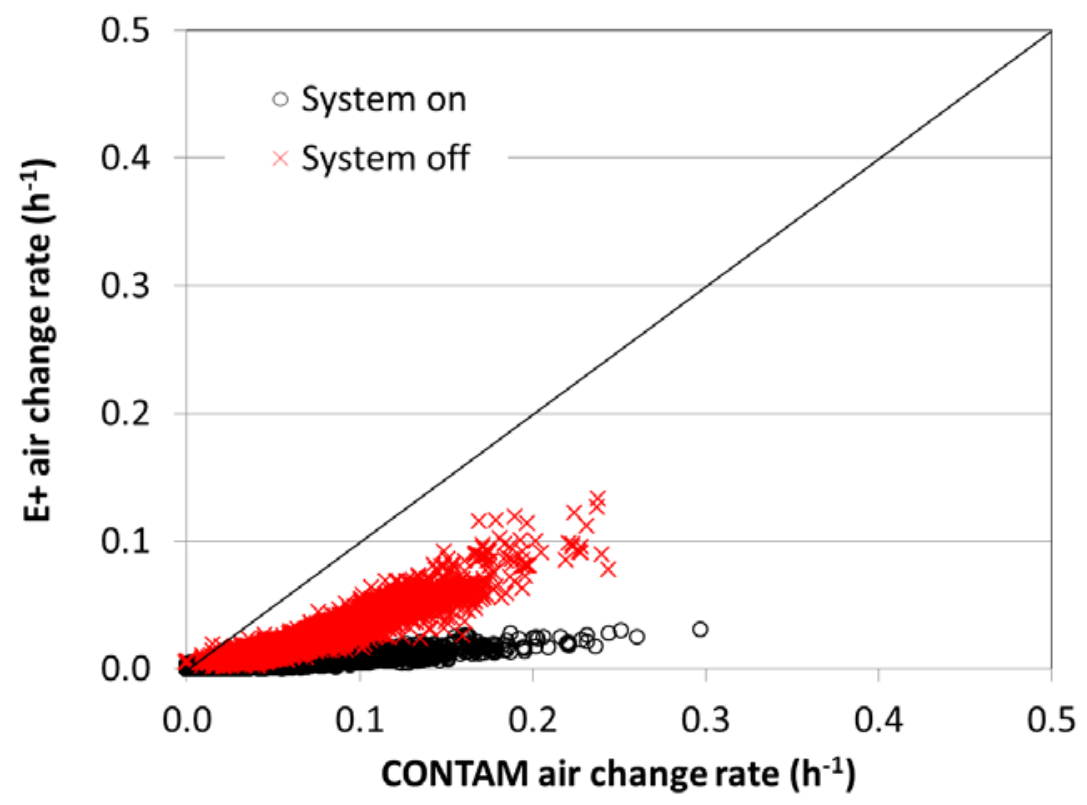

(b)

Figure 9: EnergyPlus vs. CONTAM infiltration rates for (a) Large Office and (b) Small Office (low $I_{\text {design }}$ ) 


\section{Primary School}

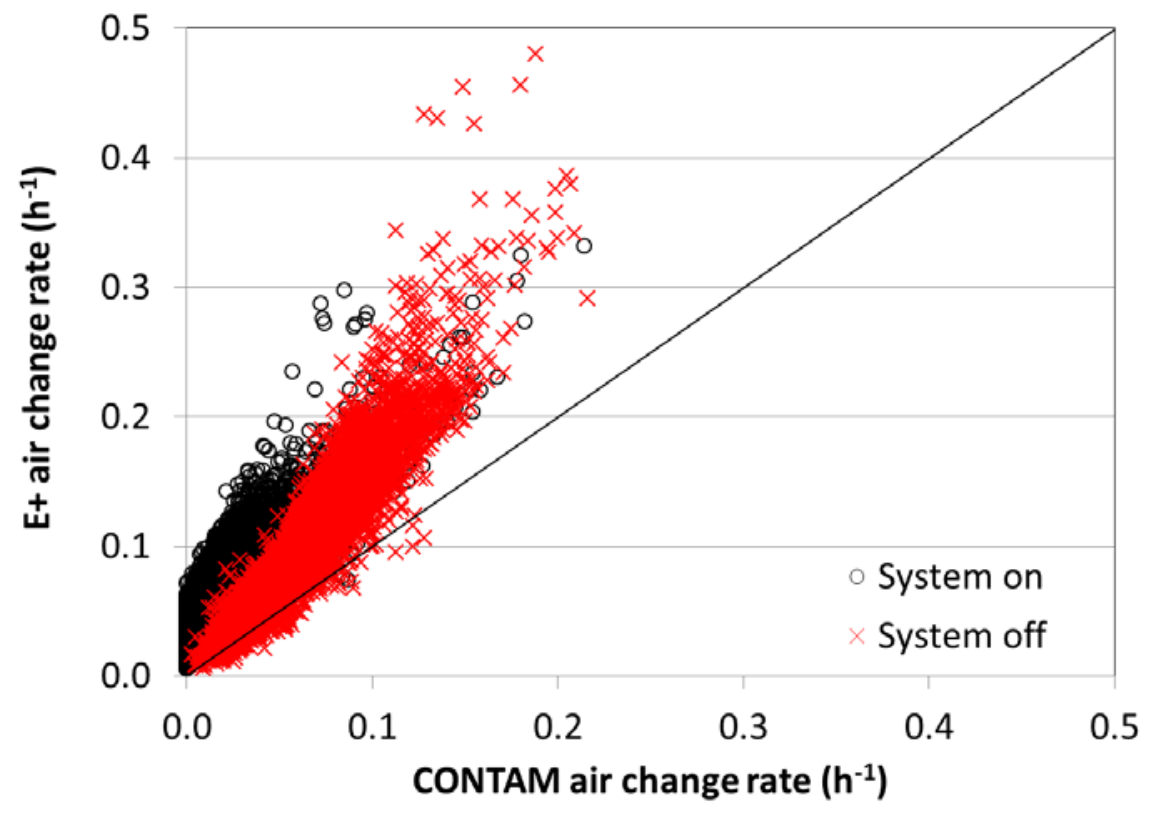

(a)

Hospital (on)

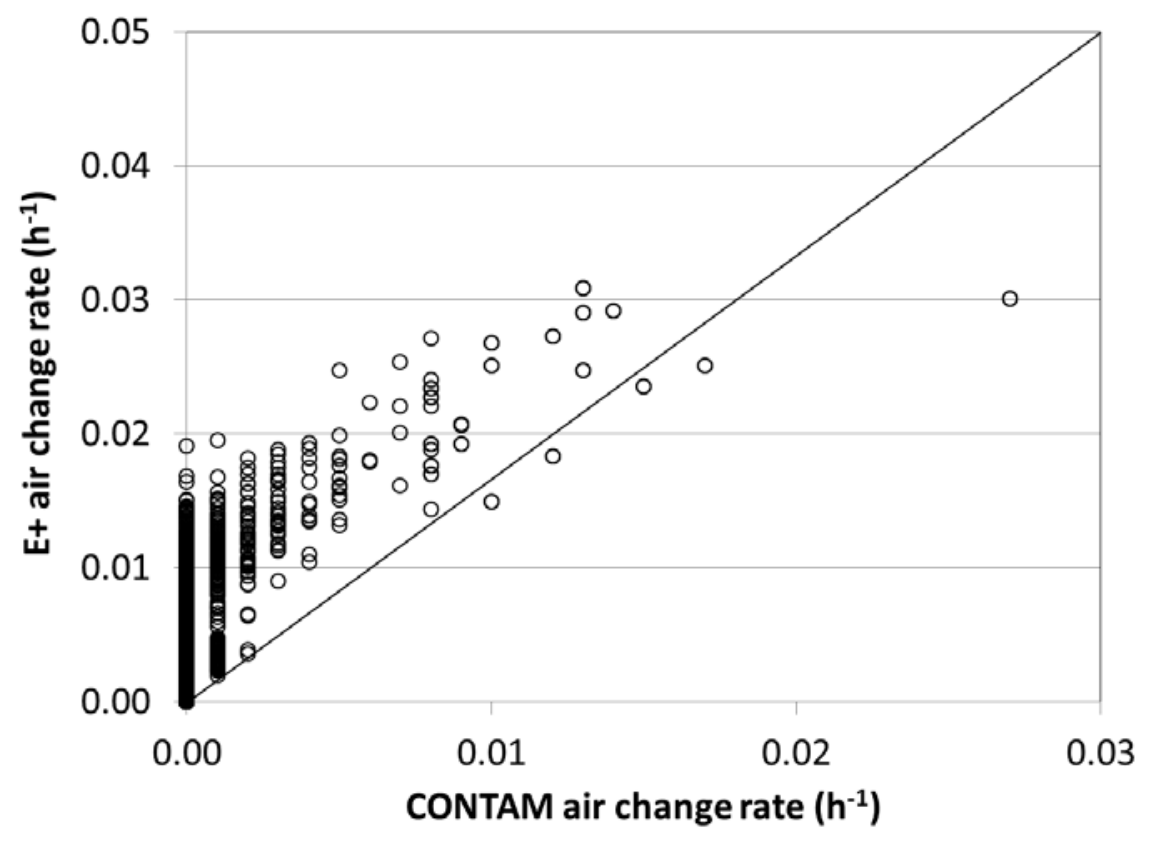

(b)

Figure 10: EnergyPlus vs. CONTAM infiltration rates for (a) Primary School and (b) Hospital (low $\left.I_{\text {design}}\right)$ 


\section{Stand Alone Retail}

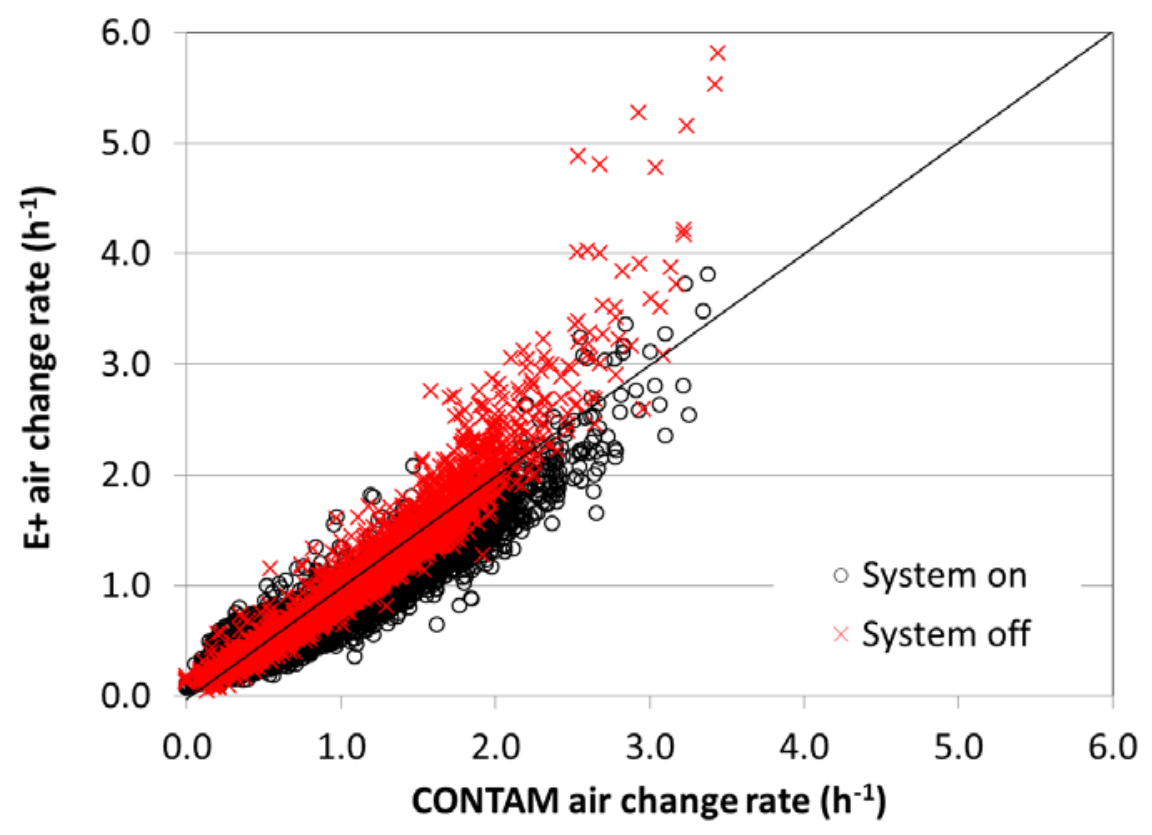

(a)

Small Hotel

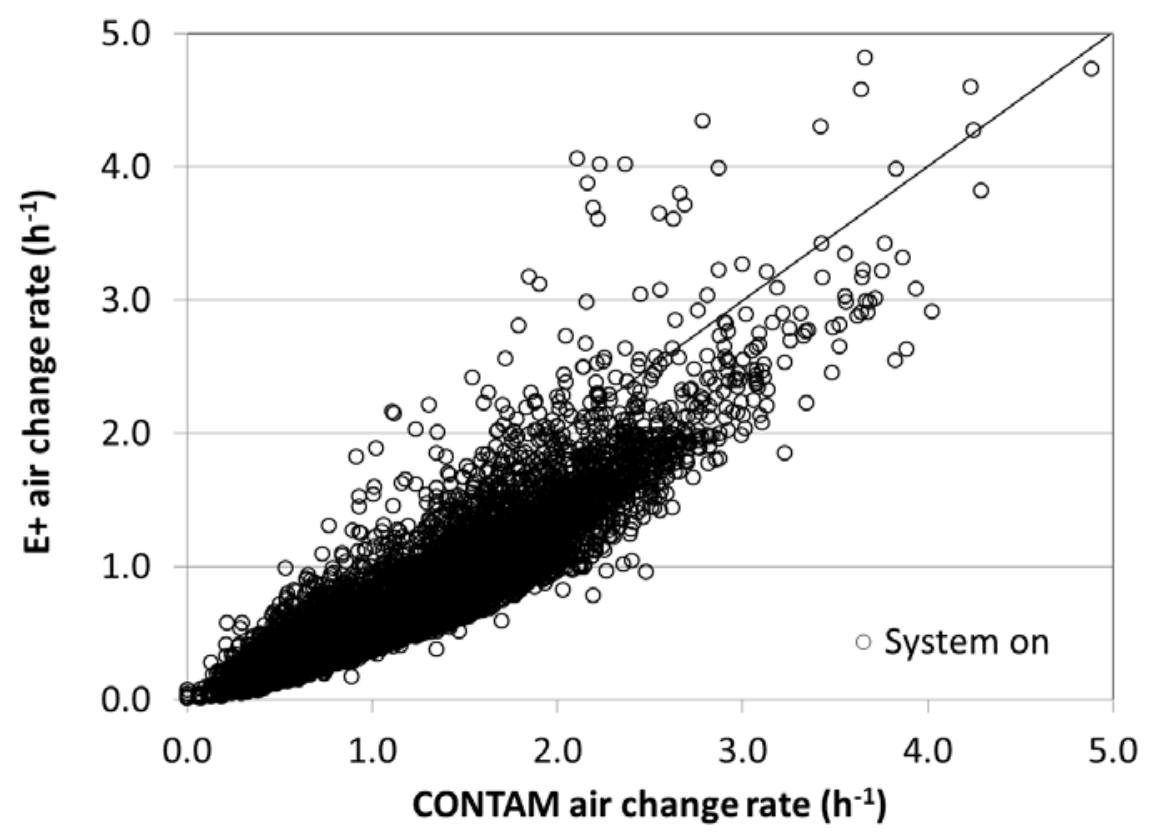

(b)

Figure 11: EnergyPlus vs. CONTAM infiltration rates for (a) Stand Alone Retail and (b) Small Office (high $\left.I_{\text {design}}\right)$ 


\section{Large Office}

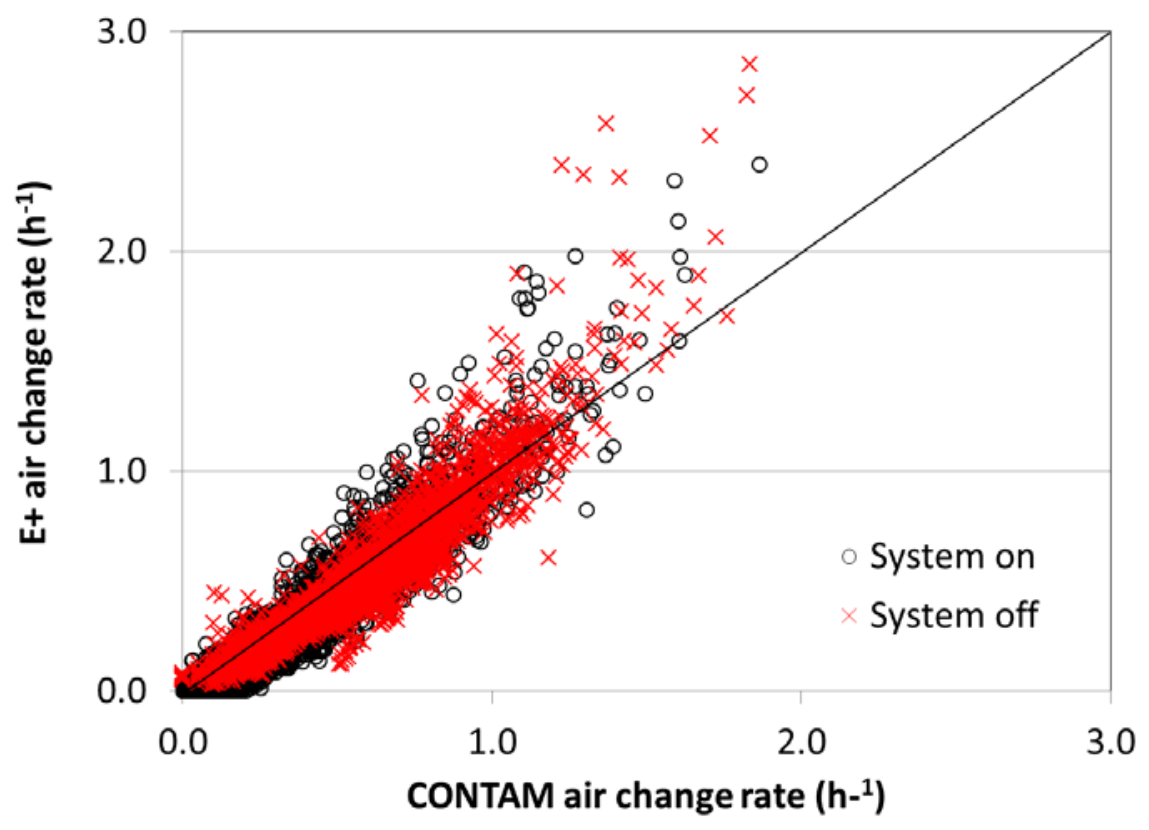

(a)

\section{Primary School}

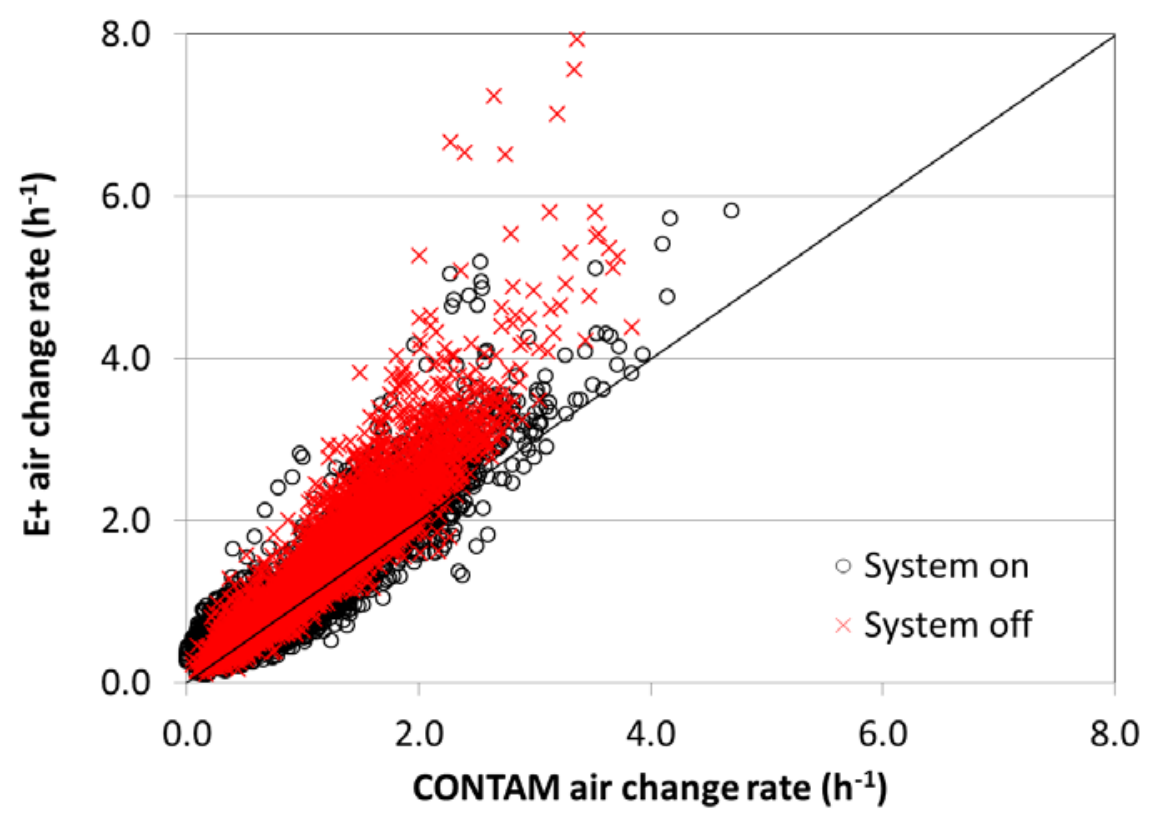

(b)

Figure 12: EnergyPlus vs. CONTAM infiltration rates for (a) Large Office and (b) Primary School (high $\left.I_{\text {design}}\right)$ 


\section{Medium Office}

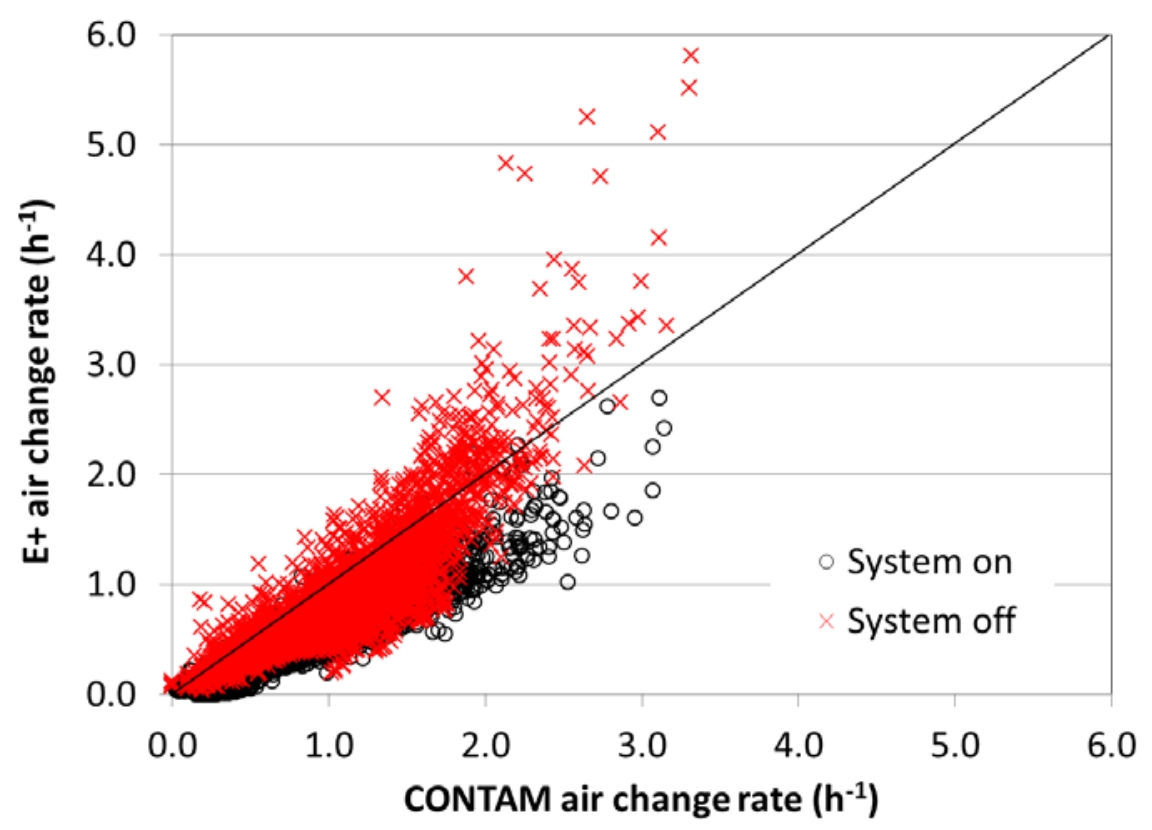

(a)

Full Service Restaurant

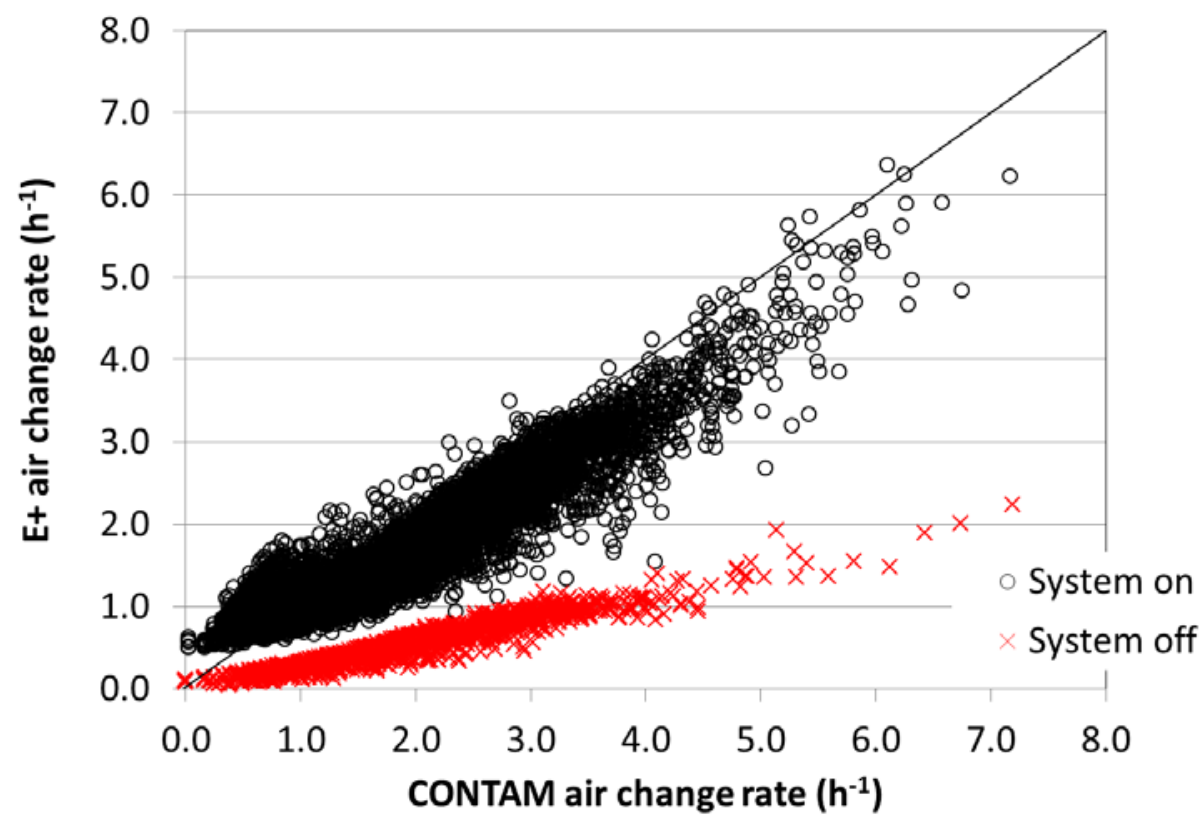

(b)

Figure 13: EnergyPlus vs. CONTAM infiltration rates for (a) Medium Office and

(b) Full Service Restaurant (high $I_{\text {design}}$ ) 
Hospital (on)

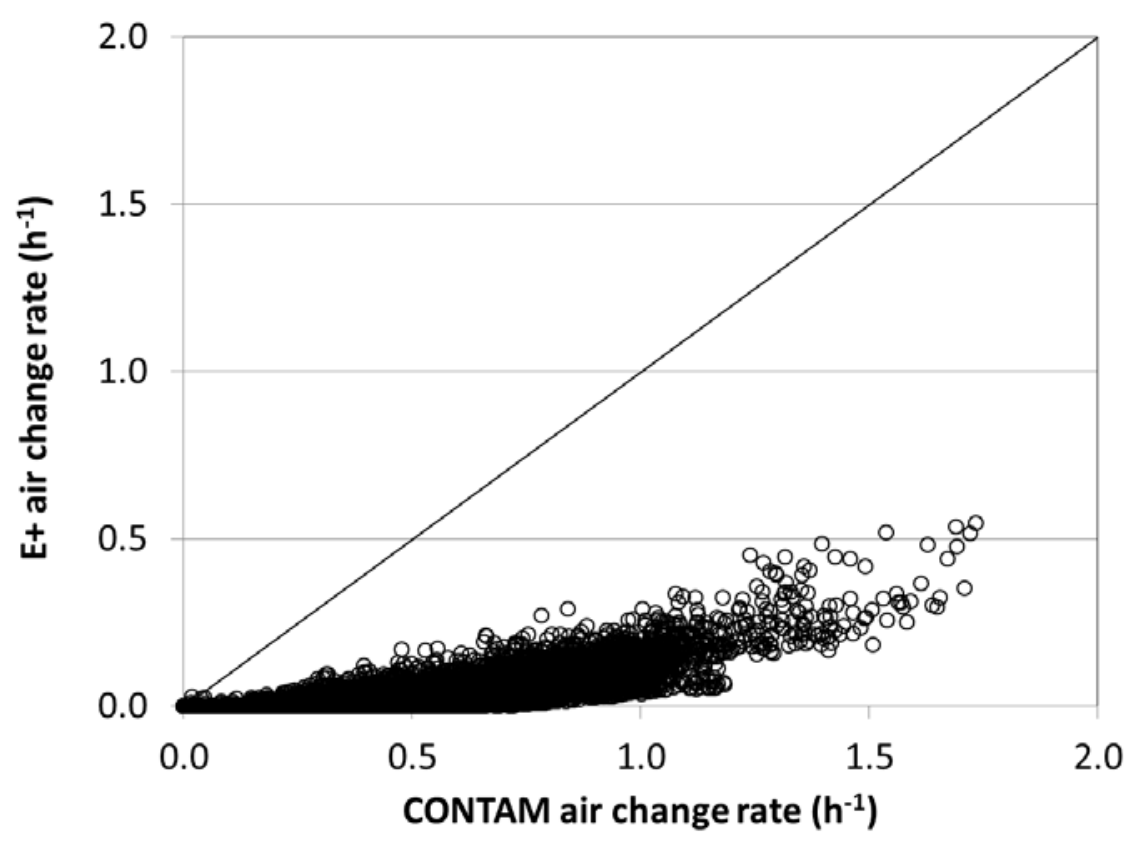

(a)

\section{Small Office}

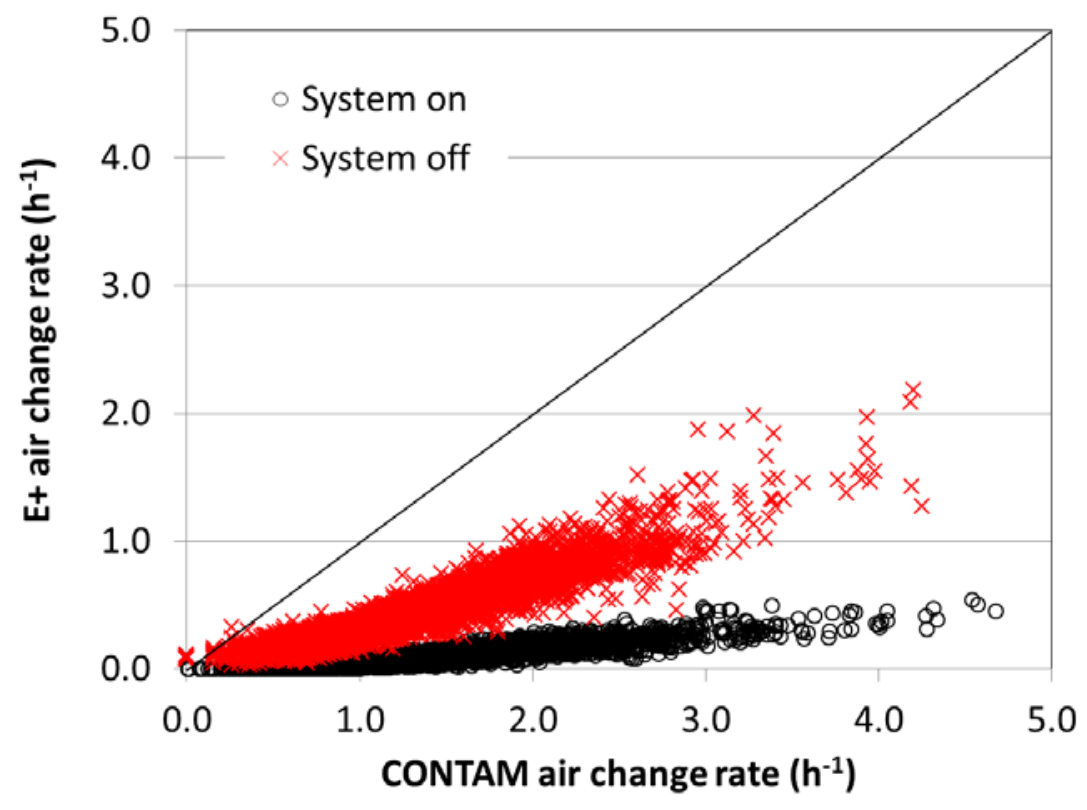

(b)

Figure 14: EnergyPlus vs. CONTAM infiltration rates for (a) Hospital and (b) Small Office (high $\left.I_{\text {design}}\right)$ 


\subsection{Comparing CONTAM rates to fixed infiltration rates in EnergyPlus}

The EnergyPlus models of the reference buildings developed by DOE (2011) implemented an infiltration modeling approach that simplified the required assumptions and reduced simulation times (Deru et al. 2011). The building envelope leakage was assumed to be $1.18 \mathrm{~cm}^{2} / \mathrm{m}^{2}$ at a constant indoor-outdoor pressure of $4 \mathrm{~Pa}$, based on a then-proposed addendum to ASHRAE 90.1-2004 for an air barrier requirement. This building envelope leakage is equivalent to an airflow rate at $4 \mathrm{~Pa}$ of $0.000302 \mathrm{~m}^{3} / \mathrm{s} \bullet \mathrm{m}^{2}$ of exterior surface area, $22 \%$ of the original $I_{\text {design }}$ value used in the simulations described above. In those EnergyPlus models, $A=1, B=C=D=0$ in Equation (1), and $F_{\text {schedule }}$ equaled 1.0 during system-on hours and was reduced to 0.25 or 0.5 during system-off hours. In other words, those models used a fixed infiltration rate that depended only on whether the system was on or off and did not consider weather effects.

It should be noted that an air barrier requirement was added to ASHRAE 90.1-2010 (ASHRAE 2010), but it does not contain a quantitative whole building airtightness requirement. Instead the standard contains material and assembly tightness requirements. Note also that the value of $1.18 \mathrm{~cm}^{2} / \mathrm{m}^{2}$ used in the DOE models is not necessarily consistent with expectations for buildings built in the two decades based on existing airtightness data (Emmerich and Persily 2005). However, the value of $5.27 \mathrm{~cm}^{2} / \mathrm{m}^{2}$ used in the CONTAM models (Section 2.2.1) is supported by consideration of these data. In addition to the building leakage value, a more important difference is that CONTAM calculates the indoor-outdoor pressure difference across the exterior envelope, while the DOE models assumed it to be a constant $4 \mathrm{~Pa}$. Assuming a constant pressure difference does not reflect known dependencies of infiltration on indooroutdoor pressure differences.

Table 12. Comparison of CONTAM and DOE fixed infiltration results (original $\boldsymbol{I}_{\text {design }}$ )

\begin{tabular}{|c|c|c|c|c|c|c|c|c|}
\hline & Restaurant & Hospital & $\begin{array}{l}\text { Large } \\
\text { Office }\end{array}$ & $\begin{array}{l}\text { Medium } \\
\text { Office }\end{array}$ & $\begin{array}{l}\text { Small } \\
\text { Office }\end{array}$ & School & Hotel & Retail \\
\hline \multicolumn{9}{|l|}{ System on } \\
\hline $\begin{array}{l}\text { CONTAM mean } \\
\text { infiltration rate }\left(\mathrm{h}^{-1}\right)\end{array}$ & 0.53 & 0.02 & 0.03 & 0.11 & 0.33 & 0.25 & 0.26 & 0.23 \\
\hline $\begin{array}{l}\text { EnergyPlus mean } \\
\text { infiltration rate }\left(\mathrm{h}^{-1}\right)\end{array}$ & 0.10 & 0.03 & 0.02 & 0.05 & 0.05 & 0.18 & 0.13 & 0.14 \\
\hline $\begin{array}{l}\text { Standard error of } \\
\text { EnergyPlus rates }\left(\mathrm{h}^{-1}\right) \\
\text { (\% of CONTAM mean) }\end{array}$ & $\begin{array}{c}0.20 \\
(38 \%)\end{array}$ & $\begin{array}{c}0.04 \\
(233 \%)\end{array}$ & $\begin{array}{c}0.04 \\
(145 \%)\end{array}$ & $\begin{array}{c}0.10 \\
(90 \%)\end{array}$ & $\begin{array}{c}0.14 \\
(43 \%)\end{array}$ & $\begin{array}{c}0.13 \\
(51 \%)\end{array}$ & $\begin{array}{c}0.12 \\
(46 \%)\end{array}$ & $\begin{array}{c}0.14 \\
(58 \%)\end{array}$ \\
\hline $\begin{array}{l}\text { Coefficient of } \\
\text { determination, } R^{2}\end{array}$ & -2.64 & -0.24 & 0.74 & 0.56 & -2.35 & -0.22 & -0.83 & -0.49 \\
\hline \multicolumn{9}{|l|}{ System off } \\
\hline $\begin{array}{l}\text { CONTAM mean } \\
\text { infiltration rate }\left(\mathrm{h}^{-1}\right)\end{array}$ & 0.50 & NA & 0.14 & 0.27 & 0.37 & 0.29 & NA & 0.26 \\
\hline $\begin{array}{l}\text { EnergyPlus mean } \\
\text { infiltration rate }\left(\mathrm{h}^{-1}\right)\end{array}$ & 0.19 & NA & 0.09 & 0.20 & 0.20 & 0.35 & NA & 0.27 \\
\hline $\begin{array}{l}\text { Standard error of } \\
\text { EnergyPlus rates }\left(\mathrm{h}^{-1}\right) \\
\text { (\% of CONTAM mean) }\end{array}$ & $\begin{array}{c}0.18 \\
(36 \%)\end{array}$ & NA & $\begin{array}{c}0.05 \\
(34 \%)\end{array}$ & $\begin{array}{c}0.08 \\
(31 \%)\end{array}$ & $\begin{array}{c}0.12 \\
(31 \%)\end{array}$ & $\begin{array}{c}0.11 \\
(37 \%)\end{array}$ & NA & $\begin{array}{c}0.09 \\
(34 \%)\end{array}$ \\
\hline $\begin{array}{l}\text { Coefficient of } \\
\text { determination, } R^{2}\end{array}$ & -1.50 & NA & 0.81 & 0.17 & -1.04 & -0.20 & NA & 0.00 \\
\hline
\end{tabular}

Note: The Hospital and Small Hotel HVAC systems are always scheduled to be on. The standard error of EnergyPlus rates and $R^{2}$ values were based on the comparison between EnergyPlus and CONTAM results. 
Summary statistics comparing use of a fixed infiltration rate in the DOE models and infiltration rates calculated by CONTAM are presented in Table 12. For most of the buildings, the infiltration rates assumed in the DOE models are less than those calculated by CONTAM, which is largely a reflection of the different building leakage values used in the two approaches. The exceptions are the Hospital and Large Office, where the infiltration rates are very low and the difference is only $0.01 \mathrm{~h}^{-1}$, but the relative standard error is more than $100 \%$. Also, the systemoff infiltration rate assumed in the DOE model of the Stand Alone Retail is similar to the mean infiltration rate calculated by CONTAM. Nevertheless, the relative standard errors using fixed infiltration rates in the DOE models are higher than they were using the Method 2 (Table 6). There are also more negative $R^{2}$ values when using assuming constant infiltration rates than there were using Method 2.

\subsection{Comparing Method 2 to PNNL approach}

As described in the Introduction to this paper, Gowri et al. (2009) proposed a method (referred to as the PNNL approach in this paper) to account for infiltration in commercial buildings. Assuming a constant indoor-outdoor pressure difference of $4 \mathrm{~Pa}$, this approach calculates an infiltration rate to be input into EnergyPlus, accounting for wind but not temperature effects using the following equation:

$$
\text { Infiltration }=F \bullet I_{\text {design }} \bullet 0.224 \cdot W_{\mathrm{s}}
$$

where $F$ is 0.25 when the HVAC system is on and 1.0 when the HVAC system is off.

Compared with Method 2 using the original $I_{\text {design }}$ value, the relative standard error of the EnergyPlus infiltration rates were higher when calculated using the PNNL approach with the same original $I_{\text {design }}$ value as shown in Table 13. For instance, the system-on relative standard error of the EnergyPlus infiltration rates for the Stand Alone Retail was $20 \%$ for Method 2 (Table 6) but increases to $38 \%$ using the PNNL approach (Table 13). Figure 15(a) shows that the system-on infiltration rates calculated using the PNNL approach underestimate those calculated by CONTAM. The system-off relative standard error of the EnergyPlus infiltration rates for the Stand Alone Retail was $13 \%$ for Method 2 (Table 6). This error increased to $35 \%$ using the PNNL approach (Table 13). Figure 15(a) shows more scatter at the lower values of the system-off infiltration rates calculated using the PNNL approach.

The system-on relative standard error of the EnergyPlus infiltration rates for the Hospital was $130 \%$ (Table 6) and $208 \%$ for the PNNL approach (Table 13). The $R^{2}$ value also decreased from -0.23 (Table 6 ) to -6.67 (Table 13). Figure 15(b) shows that the system-on infiltration rates calculated using the PNNL approach overestimate those calculated by CONTAM.

Compared with Method 2, the $R^{2}$ value of the EnergyPlus infiltration rates calculated using the PNNL approach were negative in more buildings. Using Method 2, two of the system-on cases had negative $R^{2}$ values, compared with seven of the eight system-on cases for the PNNL approach. Also, two of the system-off cases had negative $R^{2}$ values for Method 2, whereas four of the six system-off cases did using the PNNL approach. 
The differences between the infiltration rates calculated using CONTAM, Method 2, and the PNNL approach are more evident when the infiltration rates are plotted against indoor-outdoor temperature differences $(\Delta T)$. From Figure 16, it is clear that the infiltration rates calculated using the PNNL approach have no temperature dependency. For the Stand Alone Retail in Figure 16(a), the infiltration rates calculated using Method 2 agree fairly well with those calculated using CONTAM. For the Hospital in Figure 16(b), the infiltration rates calculated using Method 2 underestimate those calculated using CONTAM. Nevertheless, a small amount of temperature dependency is reflected in the infiltration rates calculated using Method 2. More scatter is observed in the infiltration rates calculated using the PNNL approach when compared with the infiltration rates calculated using CONTAM or Method 2.

When using the low $I_{\text {design }}$ value and the PNNL approach, Table 14 shows that the system-on relative standard errors of the calculated infiltration rates are higher than when using the original $I_{\text {design }}$ value (Table 13). On the other hand, Table 14 shows that the system-off relative standard errors of the calculated infiltration rates are relatively close to those for the original $I_{\text {design }}$ value (Table 13). Nevertheless, both the system-on and system-off relative standard errors of the infiltration rates calculated using the PNNL approach are higher than for Method 2 (Table 10).

When using the high $I_{\text {design }}$ value and the PNNL approach, Table 15 shows that both the systemon and system-off relative standard errors of the infiltration rates are similar to the errors when using the original $I_{\text {design }}$ value. The only exception is for the Hospital, where the relative standard error decreased significantly from $208 \%$ (Table 13) to $47 \%$ (Table 15). As was the case when using the low $I_{\text {design }}$ value, both the system-on and system-off relative standard errors of the infiltration rates calculated using the PNNL approach are higher than when using Method 2 (Table 11).

Table 13. Comparison of CONTAM and EnergyPlus infiltration rates using PNNL approach (original $\boldsymbol{I}_{\text {design})}$

\begin{tabular}{|c|c|c|c|c|c|c|c|c|}
\hline & Restaurant & Hospital & $\begin{array}{l}\text { Large } \\
\text { Office }\end{array}$ & $\begin{array}{c}\text { Medium } \\
\text { Office }\end{array}$ & $\begin{array}{l}\text { Small } \\
\text { Office }\end{array}$ & School & Hotel & Retail \\
\hline \multicolumn{9}{|l|}{ System on } \\
\hline $\begin{array}{l}\text { CONTAM mean } \\
\text { infiltration rate }\left(\mathrm{h}^{-1}\right)\end{array}$ & 0.53 & 0.02 & 0.03 & 0.11 & 0.33 & 0.25 & 0.26 & 0.23 \\
\hline $\begin{array}{l}\text { EnergyPlus mean } \\
\text { infiltration rate }\left(\mathrm{h}^{-1}\right)\end{array}$ & 0.04 & 0.19 & 0.05 & 0.08 & 0.04 & 0.09 & 0.09 & 0.08 \\
\hline $\begin{array}{l}\text { Standard error of } \\
\text { EnergyPlus rates }\left(\mathrm{h}^{-1}\right) \\
(\% \text { of CONTAM mean) }\end{array}$ & $\begin{array}{c}0.17 \\
(33 \%)\end{array}$ & $\begin{array}{c}0.04 \\
(208 \%)\end{array}$ & $\begin{array}{c}0.02 \\
(91 \%)\end{array}$ & $\begin{array}{c}0.05 \\
(47 \%)\end{array}$ & $\begin{array}{c}0.12 \\
(36 \%)\end{array}$ & $\begin{array}{c}0.09 \\
(36 \%)\end{array}$ & $\begin{array}{c}0.10 \\
(38 \%)\end{array}$ & $\begin{array}{c}0.09 \\
(38 \%)\end{array}$ \\
\hline $\begin{array}{l}\text { Coefficient of } \\
\text { determination, } R^{2}\end{array}$ & -3.23 & -6.67 & -0.70 & 0.57 & -2.27 & -0.72 & -1.02 & -1.02 \\
\hline \multicolumn{9}{|l|}{ System off } \\
\hline $\begin{array}{l}\text { CONTAM mean } \\
\text { infiltration rate }\left(\mathrm{h}^{-1}\right)\end{array}$ & 0.50 & NA & 0.14 & 0.27 & 0.37 & 0.29 & NA & 0.26 \\
\hline $\begin{array}{l}\text { EnergyPlus mean } \\
\text { infiltration rate }\left(\mathrm{h}^{-1}\right)\end{array}$ & 0.14 & NA & 0.18 & 0.26 & 0.15 & 0.30 & NA & 0.25 \\
\hline $\begin{array}{l}\text { Standard error of } \\
\text { EnergyPlus rates }\left(\mathrm{h}^{-1}\right) \\
(\% \text { of CONTAM mean) }\end{array}$ & $\begin{array}{c}0.17 \\
(33 \%)\end{array}$ & NA & $\begin{array}{c}0.05 \\
(33 \%)\end{array}$ & $\begin{array}{c}0.10 \\
(36 \%)\end{array}$ & $\begin{array}{c}0.13 \\
(36 \%)\end{array}$ & $\begin{array}{c}0.09 \\
(31 \%)\end{array}$ & NA & $\begin{array}{c}0.09 \\
(35 \%) \\
\end{array}$ \\
\hline $\begin{array}{l}\text { Coefficient of } \\
\text { determination, } R^{2}\end{array}$ & -1.72 & NA & -3.13 & -0.57 & -1.30 & 0.42 & NA & 0.42 \\
\hline
\end{tabular}

Note: The Hospital and Small Hotel HVAC systems are always scheduled to be on. The standard error of EnergyPlus rates and $R^{2}$ values were based on the comparison between EnergyPlus and CONTAM results. 


\section{Stand Alone Retail}

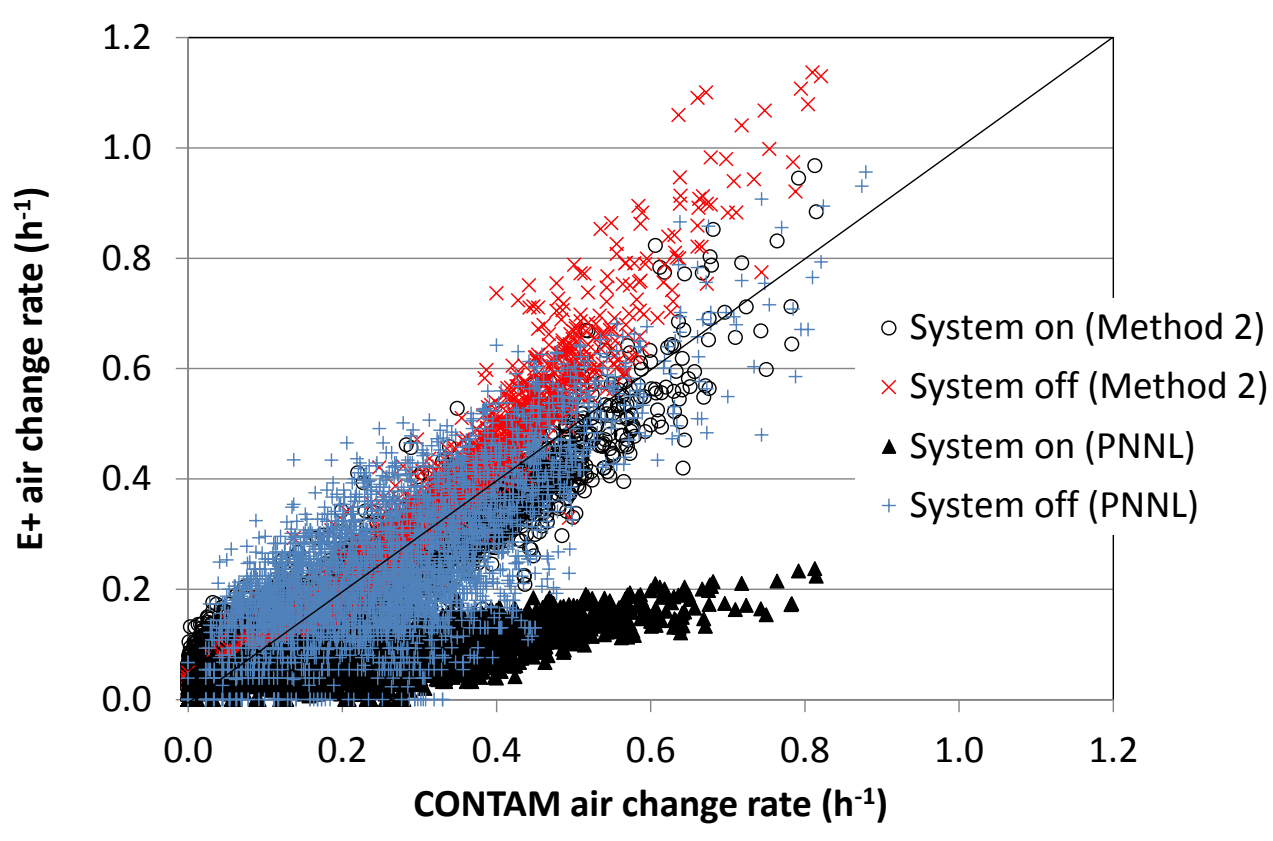

(a)

\section{Hospital}

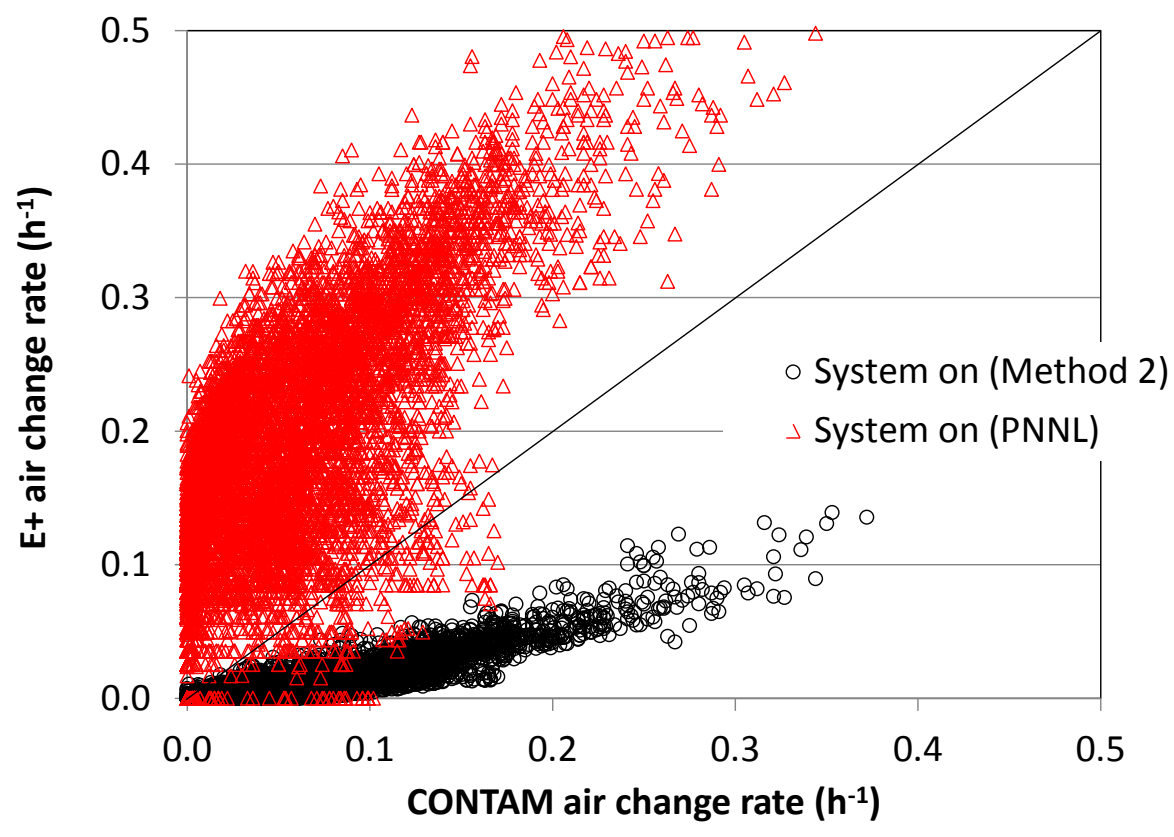

(b)

Figure 15: EnergyPlus (Method 2 and PNNL approach) vs. CONTAM infiltration rates for (a) Stand Alone Retail and (b) Hospital (original $\boldsymbol{I}_{\text {design }}$ ) 


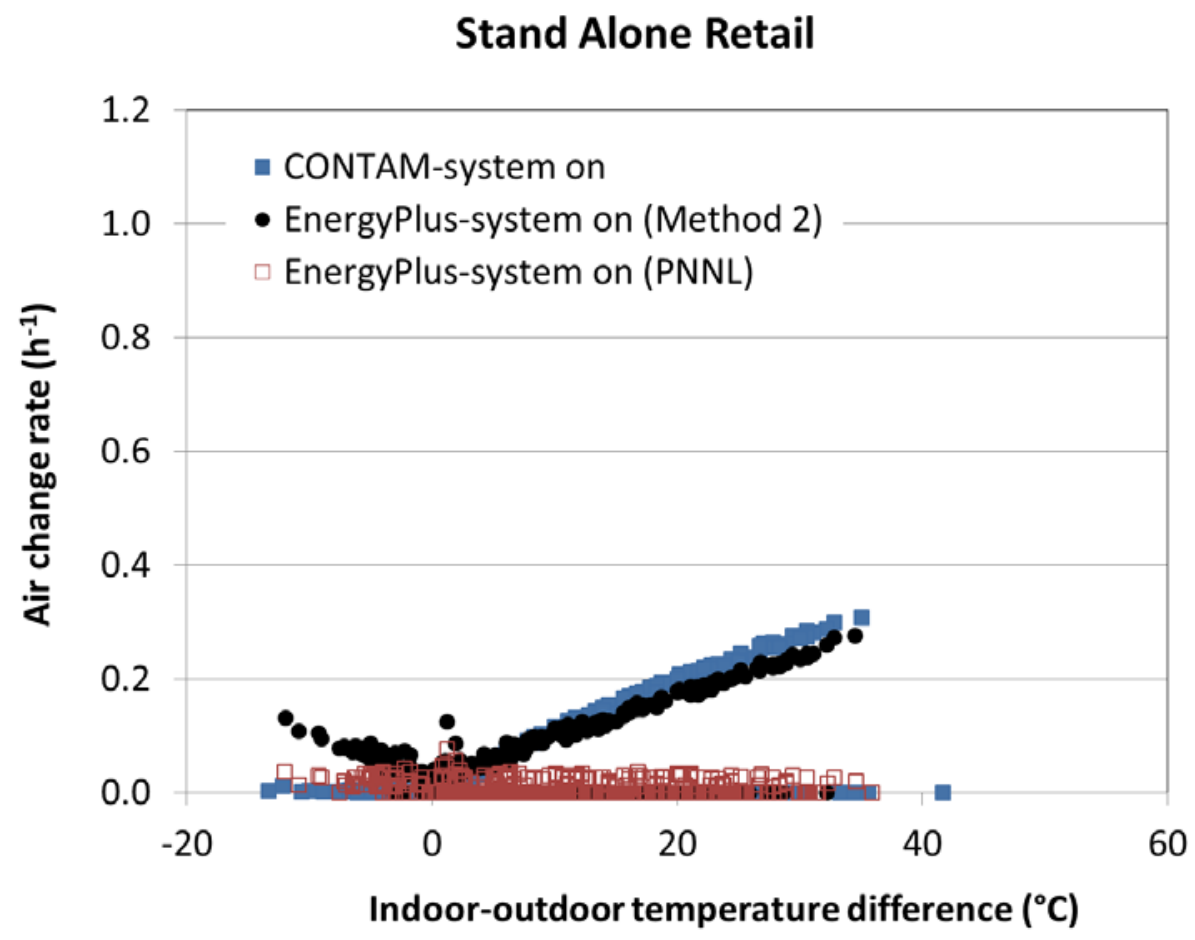

(a)

\section{Hospital}

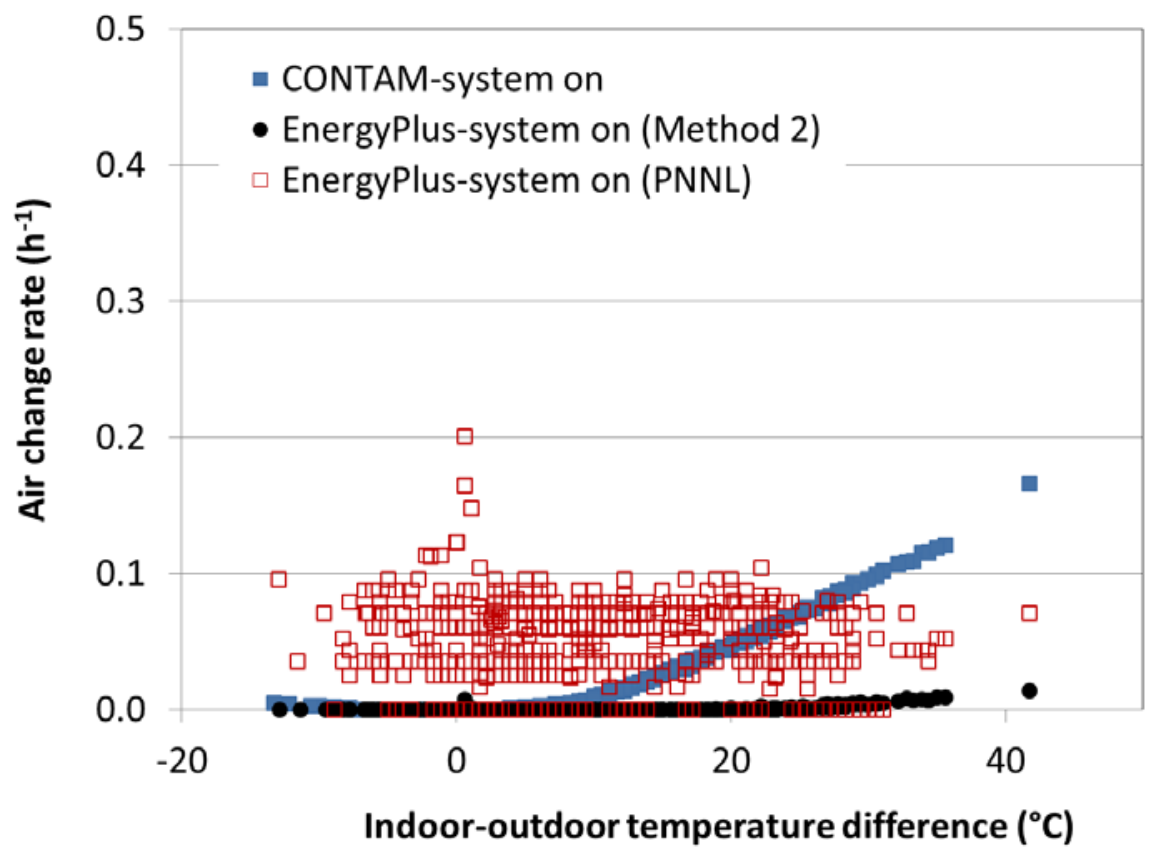

(b)

Figure 16: EnergyPlus (Method 2 and PNNL approach) and CONTAM infiltration rates vs. indoor-outdoor temperature for (a) Stand Alone Retail and (b) Hospital (original $I_{\text {design; }}$; wind speeds $<2 \mathrm{~m} / \mathrm{s}$ ) 
Table 14. Comparison of CONTAM and EnergyPlus infiltration results using PNNL approach (low $\boldsymbol{I}_{\text {design}}$ )

\begin{tabular}{|c|c|c|c|c|c|c|c|c|}
\hline & Restaurant & Hospital & $\begin{array}{l}\text { Large } \\
\text { Office }\end{array}$ & $\begin{array}{c}\text { Medium } \\
\text { Office }\end{array}$ & $\begin{array}{l}\text { Small } \\
\text { Office }\end{array}$ & School & Hotel & Retail \\
\hline \multicolumn{9}{|l|}{ System on } \\
\hline $\begin{array}{l}\text { CONTAM mean } \\
\text { infiltration rate }\left(\mathrm{h}^{-1}\right)\end{array}$ & 0.12 & 0.0001 & 0.00003 & 0.002 & 0.05 & 0.02 & 0.03 & 0.03 \\
\hline $\begin{array}{l}\text { EnergyPlus mean } \\
\text { infiltration rate }\left(\mathrm{h}^{-1}\right)\end{array}$ & 0.01 & 0.0467 & 0.01 & 0.02 & 0.01 & 0.02 & 0.04 & 0.02 \\
\hline $\begin{array}{l}\text { Standard error of } \\
\text { EnergyPlus rates }\left(\mathrm{h}^{-1}\right) \\
(\% \text { of CONTAM mean) }\end{array}$ & $\begin{array}{c}0.04 \\
(33 \%)\end{array}$ & $\begin{array}{l}0.0007 \\
(799 \%)\end{array}$ & $\begin{array}{l}0.0003 \\
(936 \%)\end{array}$ & $\begin{array}{c}0.01 \\
(293 \%)\end{array}$ & $\begin{array}{c}0.02 \\
(41 \%)\end{array}$ & $\begin{array}{c}0.01 \\
(58 \%)\end{array}$ & $\begin{array}{c}0.01 \\
(34 \%)\end{array}$ & $\begin{array}{c}0.01 \\
(49 \%)\end{array}$ \\
\hline $\begin{array}{l}\text { Coefficient of } \\
\text { determination, } R^{2}\end{array}$ & -3 & -4880 & -3260 & -7 & -0.77 & 0.49 & 0.66 & 0.37 \\
\hline \multicolumn{9}{|l|}{ System off } \\
\hline $\begin{array}{l}\text { CONTAM mean } \\
\text { infiltration rate }\left(\mathrm{h}^{-1}\right)\end{array}$ & 0.11 & NA & 0.03 & 0.06 & 0.08 & 0.07 & NA & 0.06 \\
\hline $\begin{array}{l}\text { EnergyPlus mean } \\
\text { infiltration rate }\left(\mathrm{h}^{-1}\right)\end{array}$ & 0.03 & NA & 0.05 & 0.07 & 0.04 & 0.08 & NA & 0.06 \\
\hline $\begin{array}{l}\text { Standard error of } \\
\text { EnergyPlus rates }\left(\mathrm{h}^{-1}\right) \\
(\% \text { of CONTAM mean) }\end{array}$ & $\begin{array}{c}0.04 \\
(33 \%)\end{array}$ & NA & $\begin{array}{c}0.011 \\
(33 \%)\end{array}$ & $\begin{array}{c}0.02 \\
(36 \%)\end{array}$ & $\begin{array}{c}0.03 \\
(36 \%)\end{array}$ & $\begin{array}{c}0.02 \\
(31 \%)\end{array}$ & NA & $\begin{array}{c}0.02 \\
(35 \%)\end{array}$ \\
\hline $\begin{array}{l}\text { Coefficient of } \\
\text { determination, } R^{2}\end{array}$ & -1.51 & NA & -2.81 & -0.45 & -1.06 & 0.19 & NA & 0.34 \\
\hline
\end{tabular}

Note: The Hospital and Small Hotel HVAC systems are always scheduled to be on. The standard error of EnergyPlus rates and $R^{2}$ values were based on the comparison between EnergyPlus and CONTAM results.

Table 15. Comparison of CONTAM and EnergyPlus infiltration results using PNNL approach (high $I_{\text {design }}$ )

\begin{tabular}{|c|c|c|c|c|c|c|c|c|}
\hline & Restaurant & Hospital & $\begin{array}{l}\text { Large } \\
\text { Office }\end{array}$ & $\begin{array}{c}\text { Medium } \\
\text { Office }\end{array}$ & $\begin{array}{l}\text { Small } \\
\text { Office }\end{array}$ & School & Hotel & Retail \\
\hline \multicolumn{9}{|l|}{ System on } \\
\hline $\begin{array}{l}\text { CONTAM mean } \\
\text { infiltration rate }\left(\mathrm{h}^{-1}\right)\end{array}$ & 2.05 & 0.51 & 0.36 & 0.77 & 1.38 & 1.14 & 1.21 & 1.04 \\
\hline $\begin{array}{l}\text { EnergyPlus mean } \\
\text { infiltration rate }\left(\mathrm{h}^{-1}\right)\end{array}$ & 0.17 & 0.75 & 0.21 & 0.41 & 0.18 & 0.35 & 0.35 & 0.31 \\
\hline $\begin{array}{l}\text { Standard error of } \\
\text { EnergyPlus rates }\left(\mathrm{h}^{-1}\right) \\
(\% \text { of CONTAM mean) }\end{array}$ & $\begin{array}{c}0.65 \\
(32 \%)\end{array}$ & $\begin{array}{c}0.24 \\
(47 \%)\end{array}$ & $\begin{array}{c}0.11 \\
(32 \%)\end{array}$ & $\begin{array}{c}0.25 \\
(33 \%)\end{array}$ & $\begin{array}{c}0.43 \\
(31 \%)\end{array}$ & $\begin{array}{c}0.38 \\
(33 \%)\end{array}$ & $\begin{array}{c}0.43 \\
(35 \%)\end{array}$ & $\begin{array}{c}0.38 \\
(36 \%)\end{array}$ \\
\hline $\begin{array}{l}\text { Coefficient of } \\
\text { determination, } R^{2}\end{array}$ & -3.29 & -0.62 & 0.54 & -0.10 & -3.09 & -1.21 & -1.66 & -1.44 \\
\hline \multicolumn{9}{|l|}{ System off } \\
\hline $\begin{array}{l}\text { CONTAM mean } \\
\text { infiltration rate }\left(\mathrm{h}^{-1}\right)\end{array}$ & 1.95 & NA & 0.53 & 1.01 & 1.39 & 1.16 & NA & 1.04 \\
\hline $\begin{array}{l}\text { EnergyPlus mean } \\
\text { infiltration rate }\left(\mathrm{h}^{-1}\right)\end{array}$ & 0.54 & NA & 0.72 & 1.38 & 0.60 & 1.22 & NA & 0.99 \\
\hline $\begin{array}{l}\text { Standard error of } \\
\text { EnergyPlus rates }\left(\mathrm{h}^{-1}\right) \\
(\% \text { of CONTAM mean) }\end{array}$ & $\begin{array}{c}0.63 \\
(32 \%)\end{array}$ & NA & $\begin{array}{c}0.16 \\
(30 \%)\end{array}$ & $\begin{array}{c}0.35 \\
(34 \%)\end{array}$ & $\begin{array}{r}0.48 \\
(35 \%)\end{array}$ & $\begin{array}{c}0.36 \\
(31 \%)\end{array}$ & NA & $\begin{array}{c}0.37 \\
(35 \%)\end{array}$ \\
\hline $\begin{array}{l}\text { Coefficient of } \\
\text { determination, } R^{2}\end{array}$ & -1.69 & NA & -3.69 & -0.76 & -1.14 & 0.41 & NA & 0.42 \\
\hline
\end{tabular}

Note: The Hospital and Small Hotel HVAC systems are always scheduled to be on. The standard error of

EnergyPlus rates and $R^{2}$ values were based on the comparison between EnergyPlus and CONTAM results. 


\section{SUMMARY AND DISCUSSION}

Though modelers can account for infiltration and improved envelope airtightness with current energy simulation software, the simplified approaches employed ignore the effects of weather, system operation, and envelope leakage, or at best do not account for them very well.

Oftentimes, zero, constant or scheduled infiltration rates are input into energy simulation software due to a lack of understanding of how to more accurately account for infiltration. Also, the infiltration equations currently included in energy simulation software and guidance for input variables are based largely on research for low-rise, residential buildings. However, the interaction of weather, system operation, and envelope leakage in determining infiltration rates is fundamentally related to pressure, but the physics of these interactions are not typically or easily modeled in current energy simulation software. Multizone airflow modeling is the accepted approach to calculating infiltration, however, the current means of doing so in energy simulation programs are limited and can be cumbersome to implement.

Strategies to incorporate the effects of weather, system operation, envelope leakage, and building characteristics on infiltration are presented in this paper. Method 1 is a building-specific strategy for determining coefficients in an empirical equation available in EnergyPlus to calculate infiltration. The method improves the accuracy of the infiltration rates in EnergyPlus simulations by using the results of detailed multizone airflow simulations to calculate the coefficients in the empirical equation for a given building. When applying this method to seven of the DOE reference buildings, the average system-on and system-off $R^{2}$ value for the seven buildings is 0.80 , when comparing the rates from the CONTAM and EnergyPlus simulations. Excluding the Hospital and Large Office, which have the smallest mean infiltration rates among the buildings, the average system-on relative standard error of the other buildings is $24 \%$ and the average system-off relative standard error is $15 \%$. However, Method 1 requires infiltration rate data, such as those generated using CONTAM or measured values, which may not necessarily be available. In order to address this limitation, Method 2 is presented. Method 2 calculates the coefficients in the EnergyPlus empirical equation using key building characteristics. For all of the buildings except the Hospital and Full Service Restaurant, there is good agreement between the system-on and system-off infiltration rates calculated by CONTAM and EnergyPlus using Method 2. Though the average system-on and system-off $R^{2}$ values for the seven buildings is only 0.08 , the average system-on relative standard error, excluding the Hospital and Large Office, is $25 \%$ and the average system-off relative standard error is $17 \%$.

Method 2 was also tested on buildings other than the seven used to develop it. Using Method 2 for the Small Office reference building, EnergyPlus underestimated the CONTAM infiltration rates (Section 3.1). Method 2 was also tested on two NIST buildings in Section 0. The calculated rates were lower than the CONTAM infiltration rates for the NIST Administration Building, but there was good agreement between the calculated and CONTAM infiltration rates for the NIST TRF Building.

In Section 0, Method 2 was tested using two different building envelope airtightness values, $25 \%$ and four times a baseline value used to develop the method. For the eight buildings for which EnergyPlus models were available, Method 2 performed better for the higher building leakage value than for the lower one. 
Lastly, in Section 3.4, Method 2 was compared with the approach proposed by PNNL (Gowri et al. 2009). For all values of building envelope airtightness tested, it was found that the relative standard errors of the infiltration rates calculated using the PNNL approach were higher than when using Method 2. This was partly due to the infiltration rates calculated by the PNNL approach having no temperature dependence.

\subsection{Future work}

The proposed methods for estimating infiltration rates based on weather, system operation, building envelope airtightness, and building characteristics were developed using hourly infiltration rates from CONTAM for seven commercial building models. It is possible that these methods could be made more robust by considering other buildings, such as the complete collection of fifteen commercial building models available from DOE (2011). Also, the building models developed by DOE (2011) are based on data from real buildings, but are not actual buildings. Future work could include using building envelope airtightness values and measurements of infiltration from real buildings to further evaluate these methods. Also, Method 1 and Method 2 were developed by performing CONTAM simulations using Chicago weather data only. Future work could include the use of weather data for other climates.

In addition, future work should be considered to develop guidance on how to use both methods in EnergyPlus, or other energy simulation software. However, depending on the building, occupancy use type, building envelope airtightness, and its location, the methods may still not yield infiltration rates that are sufficiently accurate. In these situations, CONTAM or other airflow simulation program would be recommended.

\subsection{Recommendations to EnergyPlus}

Based on the physics of airflow in mechanically ventilated buildings, as reflected in the CONTAM simulation results, infiltration rates are not necessarily symmetrical around an indooroutdoor temperature difference of zero when fans are on. In such cases, the absolute value of indoor-outdoor temperature difference $(|\Delta T=0|)$ in the infiltration equation used in EnergyPlus will not accurately account for infiltration at negative indoor-outdoor temperature differences. This limitation could be overcome by allowing for negative indoor-outdoor temperature differences in the calculation of infiltration in EnergyPlus.

In addition, EnergyPlus assumes that the local wind speeds at various heights acting on the building can be calculated using a scaling factor for the wind measured at a meteorological station. However, the physics of airflow at heights close to the ground and between buildings is complex and most accurately determined by wind tunnel experiments or computational fluid dynamic (CFD) simulations. From experiments or CFD simulations, local wind pressure coefficients $\left(C_{\mathrm{p}}\right)$ can be determined and used to more accurately calculate local wind pressure on buildings. 


\section{CONCLUSIONS}

Due to an increased emphasis on energy consumption and greenhouse gas emissions, the potential savings from energy efficiency measures are often analyzed using energy simulation software. However, the impact of implementing some efficiency measures is oftentimes incomplete because building envelope infiltration is not properly accounted for. Many of the airflow estimation approaches implemented in current energy software tools are inappropriate for large buildings or are otherwise limited. Based on the relationship between building envelope airtightness, building characteristics, weather, and system operation, methods are presented in this paper to calculate infiltration rates that are comparable to performing multizone calculations. These methods show better accuracy when compared with existing approaches to estimating infiltration in commercial building energy calculations.

\section{REFERENCES}

ASHRAE (2009). ASHRAE Handbook Fundamentals. Atlanta: American Society of Heating, Refrigerating and Air-Conditioning Engineers, Inc.

ASHRAE (2010). ANSI/ASHRAE/IESNA Standard 90.1-2010: Energy Standard for Buildings Except Low-Rise Residential Buildings. Atlanta: American Society of Heating, Refrigerating and Air-Conditioning Engineers.

ASTM (2010). ASTM E779-10 Standard Test Method for Determining Air Leakage Rate by Fan Pressurization. Philadelphia: American Society of Testing and Materials.

Deru, M., K. Field, D. Studer, K. Benne, B. Griffith, P. Torcellini, B. Liu, M. Halverson, D. Winiarski, M. Rosenberg, M. Yazdanian, J. Huang and D. Crawley (2011). U.S. Department of Energy Commercial Reference Building Models of the National Building Stock. NREL/TP-5500-46861. Colorado: National Renewable Energy Laboratory. DOE (2010). Building Energy Data Book. Washington: U.S. Department of Energy. 245 pp.

DOE (2011). Commercial Reference Buildings from http://tinyurl.com/ccudjyg.

DOE (2012). EnergyPlus Input-Output Reference

DOE (2013). EnergyPlus 8.1. Washington, D. C., U. S. Department of Energy.

Emmerich, S. J., T. P. McDowell and W. Anis (2007). Simulation of the Impact of Commercial Building Envelope Airtightness on Building Energy Utilization. ASHRAE Trans. 113(2): 379-399.

Emmerich, S. J. and A. K. Persily (2005). Airtightness of Commercial Buildings in the U.S. 26th AIVC Conference, Brussels, Belgium.

Emmerich, S. J. and A. K. Persily (2013). Analysis of U. S. Commercial Building Envelope Air Leakage Database to Support Sustainable Building Design. Submitted to International Journal of Ventilation.

Gowri, K., D. Winiarski and R. Jarnagin (2009). Infiltration Modeling Guidelines for Commercial Building Energy Analysis. PNNL-18898. Richland, WA: Pacific Northwest National Laboratory.

McDowell, T. P., S. Emmerich, J. W. Thornton and G. N. Walton (2003). Integration of Airlfow and Energy Simulation Using CONTAM and TRNSYS. ASHRAE Trans. 109(2).

Ng, L. C., A. Musser, S. J. Emmerich and A. K. Persily (2012). Airflow and Indoor Air Quality Models of DOE Reference Commercial Buildings. Technical Note 1734. Gaithersburg, MD: National Institute of Standards and Technology. 
Ng, L. C., A. Musser, A. K. Persily and S. J. Emmerich (2013). Multizone airflow models for calculating infiltration rates in commercial reference buildings. Energy Build. 58(0): 1118.

Ng, L. C. and A. K. Persily (2011). Airflow and Indoor Air Quality Analyses Capabilities of Energy Simulation Software. Indoor Air 2011, Austin, TX.

Persily, A. K., R. E. Chapman, S. J. Emmerich and W. S. Dols (2007). Building Retrofits for Increased Protection Against Airborne Chemical and Biological Releases. NISTIR 7379. Gaithersburg, MD: National Institute of Standards and Technology.

Shaw, C. Y. and G. T. Tamura (1977). The Calculation of Air Infiltration Rates Caused by Wind and Stack Action for Tall Buildings. ASHRAE Trans. 83(2): 145-157.

Walton, G. N. (1989). AIRNET - A Computer Program for Building Airflow Network Modeling. Gaithersburg: National Institute of Standards and Technology.

Walton, G. N. and W. S. Dols (2013). CONTAM User Guide and Program Documentation. NISTIR 7251. Gaithersburg, MD: National Institute of Standards and Technology. 